\title{
Internalizing the externalities of overfunding: an agent-based model approach for analyzing the market dynamics on crowdfunding platforms
}

\author{
Jascha-Alexander Koch $^{1}$ (D) . Jens Lausen ${ }^{1}$ (D) Moritz Kohlhase ${ }^{1}$
}

Accepted: 11 May 2021 / Published online: 25 May 2021

(c) The Author(s) 2021

\begin{abstract}
Crowdfunding platforms offer project initiators the opportunity to acquire funds from the Internet crowd and, therefore, have become a valuable alternative to traditional sources of funding. However, some processes on crowdfunding platforms cause undesirable external effects that influence the funding success of projects. In this context, we focus on the phenomenon of project overfunding. Massively overfunded projects have been discussed to overshadow other crowdfunding projects which in turn receive less funding. We propose a funding redistribution mechanism to internalize these overfunding externalities and to improve overall funding results. To evaluate this concept, we develop and deploy an agent-based model (ABM). This $\mathrm{ABM}$ is based on a multi-attribute decision-making approach and is suitable to simulate the dynamic funding processes on a crowdfunding platform. Our evaluation provides evidence that possible modifications of the crowdfunding mechanisms bear the chance to optimize funding results and to alleviate existing flaws.
\end{abstract}

Keywords Crowdfunding · Overfunding · Internalization of externalities · Pigouvian tax $\cdot$ Agent-based modeling $\cdot$ Market engineering

JEL Classification C63 · D47 · D61 · D62 · G41

Jascha-Alexander Koch

jaskoch@wiwi.uni-frankfurt.de

Jens Lausen

lausen@wiwi.uni-frankfurt.de

Moritz Kohlhase

moritz.kohlhase@gmail.com

1 Goethe University Frankfurt, Theodor-W.-Adorno-Platz 4, 60629 Frankfurt am Main, Germany 


\section{Introduction}

The increasing availability of the Internet has continuously functioned as an important driver of innovative solutions as well as business models (Dijkman et al. 2015; Timmers 1998; Gomber et al. 2017). The idea of asking a large crowd of people to support a certain cause was not new, but the far-reaching connective power of the Internet has lived up this concept and turned it into a powerful alternative to traditional ways of financing, such as bank credits or venture capital. The fast and dynamic ascent of crowd-based approaches of acquiring capital, like crowdfunding, crowdinvesting, or P2P lending, has attracted attention not only of the capital-seeking individuals but also of academic research. Online crowdfunding platforms, i.e., the digital meeting places for money-seeking individuals and potential funders, constitute dynamic two-sided markets that bear many interesting and yet unexplored phenomena. The main focus of research has been so far on the analysis of available archival data (e.g., Koch and Siering 2015; Mollick 2014; Zvilichovsky et al. 2015), acquired survey data (e.g., Allison et al. 2014; Gerber et al. 2012), or experimental data (e.g., Burtch et al. 2015; Cholakova and Clarysse 2015). The respective research questions that have been dealt with are addressing specific phenomena that are represented by actual data, such as the funding success of projects, the funding behavior of funders, or the motivations of individuals for participating in crowdfunding. Although it has been shown that crowdfunding has a high value for society and for individuals that need financial support (Burtch and Chan 2014), some processes on crowdfunding platforms cause undesirable externalities, i.e., the processes increase the benefits of crowdfunding for some participants while reducing the benefits for other participants. However, the questions of how crowdfunding can serve best all of its stakeholders (Koch 2017) or of how to deal with negative externalities are completely underresearched. Answers to these questions are of high value for society and of special importance for platform operators since the value of crowdfunding might be considerably increased.

In the field of industrial organization, one important component is the discussion of market structure, which embraces the question of how market structure is related to market performance. Crowdfunding platforms constitute dynamic markets on which the respective market structure has an important influence on the resulting market performance and on the resulting value of crowdfunding for society and the economy. Game theory and principles of mechanism design (Hurwicz and Reiter 2006) provide the foundations for understanding how wellperforming markets evolve or can be designed. These aspects are especially important when it comes to understand and guide the behavior of crowdfunding platform participants. In the special case of crowdfunding platforms, all transactions and processes are performed and coordinated on an electronic market place, i.e., through an underlying information system. The resulting outcome of the market is not only dependent on fundamental economic processes but also on the information system and information technology. Here, the "designer of electronic markets wants to achieve a certain market outcome", however, this outcome is 
"dependent on the behavior of all market participants" (Neumann et al. 2005). While market design focuses on the game-theoretical and economical understanding of the interplay of market participants, market engineering deals with the systematic and theoretically founded analysis, development, and optimization of electronic markets (Weinhardt et al. 2003) in order to reach a certain outcome by designing the market and its rules. With our research, we contribute to this strand of literature by addressing the question of how crowdfunding serves best all of its stakeholders. Specifically, we focus on the phenomenon of overfunding of crowdfunding campaigns (Koch 2016), which is a consequence of funders' behavior. In the case of overfunding, a crowdfunding project collects much more funding compared to the actual funding goal. In this context, it has been discussed, that overfunding can cause negative externalities for other projects which are overshadowed by overfunded blockbuster projects and, thus, suffer the disadvantage of collecting less funding (Kim et al. 2016; Liu et al. 2015). We follow economic theory and propose a mechanism to internalize the externalities caused by overfunding. Specifically, we address the research question of whether a funding redistribution mechanism is able to improve overall funding results. On that account, we propose the introduction of an on-platform "taxation" mechanism that allows for redistributing funds to valuable underfunded projects to improve overall funding outcomes and analyze different approaches for implementing the "taxation" mechanism on crowdfunding platforms.

The analysis of archival or survey data is insightful and reveals interesting findings. Nevertheless, the interactive and dynamic interplay between a high number of individuals cannot be easily analyzed using this kind of data. Especially questions that concern the reaction to hypothetical environmental conditions cannot be answered only by considering such data. Thus, we deem it important that research uses its widely varied set of methods in order to address questions that could not have been answered so far in the field of crowdfunding. The effect of changes in market structure cannot be analyzed by available data and real tests would be highly costly for platforms. Against this backdrop, to evaluate our taxation approach, we propose an advanced agent-based model (ABM) reproducing and simulating a real platform system for analyzing the behavior of agents in the system. The outstanding advantage of this approach is its capability to simulate a real platform and agents' behaviors without affecting a real platform by experiments. With this powerful tool, we are able to evaluate our mechanism for internalizing overfunding externalities by applying sensitivity analysis.

We contribute to the literature on crowdfunding and market engineering by giving insights into an internalization mechanism that reduces overfunding externalities and increases the value of crowdfunding for its stakeholders. Thereby, we discuss and apply related theories in this specific case. Furthermore, we give a clear and comprehensible outline of how to develop ABMs in the field of crowdfunding which could also be used for various other academic and practical question sets.

This paper proceeds as follows. Firstly, we provide important background information on crowdfunding and connected research, on the economic theory of the internalization of externalities in general and in the context of crowdfunding. Next, we provide information on our methodology and describe how to develop an ABM 
for crowdfunding platforms. Subsequently, we evaluate our model and perform a policy experiment to discuss how to internalize the externalities of overfunding on crowdfunding platforms. We, then, discuss our results and the potential limitations and provide an outlook on future research. Finally, we conclude.

\section{Background}

\subsection{Crowdfunding and related research}

The crowd-based acquisition of funding consists of asking a large crowd of people for their financial support and collecting their relatively small monetary contributions for accomplishing a certain financial goal. On online crowdfunding platforms, money-seeking project initiators ("project creators" or "project founders") meet potential funders ("backers") that are searching for interesting projects and promising investment opportunities. In order to convince funders to support their aims, project initiators present and describe their ideas using textual information, pictures, or videos. Typically, project initiators have to determine the funding goal (e.g., USD 20,000) and the length of the funding period (e.g., 30 days). If a project succeeds in reaching the funding goal by the end of the funding period, it is successfully funded. While some platforms pay out the money independently from reaching this goal (keep-it-all model, e.g., on giveforward.com), other platforms pay out the money only if the collected funding meets or exceeds the funding goal (allor-nothing model, e.g., on kickstarter.com). Especially in the case of all-or-nothing models, which are applied on many platforms, high sums of collected funding have to be given back to the funders because the funding goal was not reached. According to which type of crowdfunding is applied, funders receive different types of compensation for their monetary support. While in reward-based crowdfunding the funders prepurchase material or immaterial (non-financial) compensations, e.g., products or services, in lending-based crowdfunding (P2P lending), funders receive repayments and interest payments. In equity-based crowdfunding (crowdinvesting), funders receive shares of a venture or some other form of participation. On the contrary, in donation-based crowdfunding, funders do not receive any compensation. However, the act of funding means psychological satisfaction through having helped other people altruistically (Gerber et al. 2012). Thus, funders derive a certain form of utility from supporting the projects even in the case of donations. The considerations concerning expected utilities are a key driver of the resulting funding decisions (Koch 2017).

Research has already explicitly dealt with certain phenomena concerning individuals' funding decision behavior. It was found that especially friends and family members are among the first to support a project (Agrawal et al. 2015). Crowdfunding campaigns that have collected higher amounts of funding profit from a herding effect that drives people to further support the project because they trust the decisions of previous funders (Zhang and Liu 2012). However, if a project is close to reaching the designated funding goal, some kind of bystander effect leads to the effect that funders "do not contribute to a project that has already received a lot of 
support because they assume that someone else will provide the remaining financing" (Kuppuswamy and Bayus 2013). Investigations also show that funders "prefer to contribute funds locally and to culturally similar others" (Burtch et al. 2014). As a consequence of such funding decisions, some projects will reach their funding goal while others fail. Funding success can, thus, be interpreted as the aggregate result of the various funding decisions.

Research has also engaged in analyzing the drivers of crowdfunding success and found several interesting factors. Most basically, it was confirmed that lower funding goals are easier to reach than higher goals (Mollick 2014). Less intuitively, it was revealed that longer funding periods of projects lead to a lower probability of funding success. It seems as if longer periods are interpreted as "a sign of lack of confidence" among project initiators (Mollick 2014). Furthermore, evidence has been found for the importance of information provision. The more textual information is given, the more likely is funding success (Barbi and Bigelli 2015; Koch and Siering 2015; Pitschner and Pitschner-Finn 2014). Moreover, pictures and graphical descriptions (Koch and Siering 2015) as well as videos (Koch and Siering 2015; Mollick 2014) support funding success. These and other insights have been used, e.g., to predict campaigns' funding success (Koch and Cheng 2016).

While such specific phenomena of crowdfunding have already gained attention in research, the superordinate question of how overall utility, i.e., the sum of all material and immaterial benefits, derived through crowdfunding could be optimized is still underresearched. From the perspective of practitioners, more specific propositions of how crowdfunding models could be enhanced are needed. Following the literature on market engineering, it is important to design electronic market places carefully while considering individuals' behavior (e.g., Neumann et al. 2005; Weinhardt et al. 2003). This strand of literature deals with the analysis, development, and optimization of electronic markets (Weinhardt et al. 2003). For reaching a certain outcome, electronic markets need conscious design and rules. An interesting starting point for improving market outcomes on crowdfunding platforms is the great difference in funding amounts that projects receive. While some projects achieve very low levels of funding, other projects reveal massive overfunding (Koch 2016). So far, the phenomenon of overfunding has been rarely addressed in research-however, if it was addressed, it was discussed controversially (e.g., Kim et al. 2016; Liu et al. 2015; Malave 2012). A statement that is regularly made in the context of overfunding is that it can cause externalities that have an impact on other projects on the platform. Here, both positive and negative external effects of overfunding are found and discussed (Doshi 2014; Kim et al. 2016; Liu et al. 2015). More specifically, in this paper, external effects on crowdfunding platforms are understood as effects that are caused by one project (or by the processes connected to this project) and have a negative effect on the funding collection of one or more other projects on the platform. One obvious reason for such effects is that crowdfunding projects on a platform compete for funding (Burtch 2011). Funds that are assigned to one project cannot be received by another project. First of all, it has been confirmed that overfunded blockbuster projects have significant external effects on other projects (e.g., Kim et al. 2016; Liu et al. 2015). Here, it was shown that massively overfunded projects can have a positive effect on "related projects". In other words, these projects 
profit from the existence of overfunded blockbuster projects (Kim et al. 2016; Liu et al. 2015). Hereby, the term "related" means that campaigns are in the same project category and reveal a high textual similarity regarding their project description. However, while some projects seem to benefit, it has been revealed that overfunded projects "hurt the performance of less-related projects" (Liu et al. 2015). As a consequence, a great number of projects is adversely influenced concerning the funding performance, since it can be assumed that there are typically more unrelated than related projects on a platform. Kim et al. (2016) confirm that there is a significant "cannibalization effect of blockbuster projects" on projects of other topics. Doshi (2014) even suggests that project initiators choose the "option of not entering" the platform with a new project because they fear to be outshined by the blockbuster projects. Kim et al. (2016) also find indication that some project initiators refuse to start new projects on the platform if there are massively overfunded blockbuster projects. Such empirical findings make us believe that overfunding cannot just be seen as a positive phenomenon in crowdfunding. This opinion finds support by a range of further facts. Mollick (2014), for example, concludes that overfunded projects are "particularly vulnerable to delay" concerning the delivery of rewards. This constitutes a negative effect for funders who have to wait much longer for their funding compensations as promised. Moreover, there are well-known overfunded projects that have struggled and have left behind a big crowd of disappointed funders (like, e.g., the Coolest Cooler, or the video game console OUYA). Here, we argue that a concentration of funders on highly overfunded projects leads to a concentration of risk. If an overfunded project fails or cannot fulfill its promises concerning the rewards, it is more likely to trigger negative publicity for the platform than a number of less funded projects. Such examples of negative external effects can be seen as possible symptoms of market failure (Williamson 1971). As a result, the funding outcomes may be biased rather than reflecting optimal funding results (Koch 2016).

\subsection{Internalization of external effects}

From a theoretical perspective, external effects or externalities are central to the "critique of market organization" (Buchanan and Stubblebine 1962). Externalities are present when there is a "divergence between private and social costs" (Dahlman 1979). If so, the utility of an individual is not only dependent on his/her own activities, but also on the activities of other individuals. Externalities can be positive or negative and they have a considerable impact on the transactions that are made on markets. Without intervention (i.e., internalizing the externalities), some potential beneficial transactions are not realized-which harms the performance of markets and leads to market failure (Dahlman 1979). In economic theory, the internalization of externalities is a widely discussed approach to prevent market failure or to reduce its consequences for individuals and the society. For the elimination or reduction of external effects, elements of the Coasian (Coase 1960) and the Pigouvian (Pigou 1920) approaches are considered (Aidt 1998). Both approaches have the goal to reallocate resources in order to eliminate or prevent market failure caused by external effects. While the Coasian approach encourages an efficient resource allocation 
through negotiation of the involved parties (Coase 1960), the goal of the Pigouvian approach is to impose a tax — the so-called Pigouvian tax —on negative externalities, so that emerging external costs are carried by the perpetrator. Due to the tax, the economic acting and the behavior of the perpetrator is to be redirected in a desirable direction (Pigou 1920).

As a practical proceeding for internalizing externalities, Gupta and Prakash (1993) propose four steps: (1) the (negative) externalities need to be recognized, (2) the perpetrator and the potential victim must be identified, (3) for each party, costs and benefits of internalization need to be evaluated, and (4) the costs and benefits of internalization need to be assigned. For the assignment of costs and benefits, the policy maker needs to decide which mechanism to use. Since the mechanism depends on the purpose, different approaches are discussed in academic literature, e.g., for environmental policy (Baumol and Oates 1971) or regulating systemic risk in the financial sector (Acharya et al. 2010). We argue that the internalization of external effects is also valuable to be discussed in the context of crowdfunding.

Against the backdrop of having some crowdfunding projects worth to be funded, which fail to reach their funding goal, we decide to contribute to the discussion by addressing the negative externalities of overfunded projects. We aim at clarifying whether a funding redistribution mechanism is able to improve funding outcomes on a platform. Inspired by the Pigouvian tax, we develop a funding redistribution approach that imposes a tax on funding that goes beyond a project's funding goal. However, according to the Pigouvian approach (Pigou 1920), the tax needs to reflect the negative consequences that all other individuals experience. Instead, our approach primarily aims at achieving the best funding results and is not directly based on individuals' costs. This has the advantage that costs do not need to be expressed in monetary units. Moreover, the tax yield is not used to compensate all individuals' costs, but is distributed to selected valuable projects that have closely missed their funding goal. Thus, we do not claim to fulfill the requirements of the Pigouvian tax and just call it "tax" instead. Further, we are aware of that a tax usually is imposed by governments and that our approach represents a compensation payment used as market engineering instrument. Still, the functionality is inspired by a taxation approach. As actual platform data is not able to analyze the effect of such a tax, we choose an approach based on an agent-based model simulating the processes of a crowdfunding platform.

\section{Analyzing an internalization approach for overfunding on crowdfunding platforms}

For platform operators, it can turn out to be disadvantageous to run real tests on the platform for potential modifications or new models since this could possibly lead to unexpected consequences and costs. With ABMs' capabilities to simulate individuals' decision-making behavior, it is possible to model platforms in order to analyze the emergent reactions of its users, e.g., in case of modifications. Such investigations are of high value in the context of crowdfunding platforms. Agent-based modeling has become a widespread and common tool for analyzing complex socio-technical 
systems in diverse academic disciplines (Nikolic and Ghorbani 2011; Klein et al. 2018). An important reason for this increase in applications is the fact that purely mathematical models have their limits when it comes to modeling complex dynamic systems that reveal diverse interactions, adaptations, or changing conditions (Bonabeau 2002). Especially modeling heterogeneity, e.g., of individuals' decision-making behavior, is a big issue. In contrast to mathematical models, ABMs allow for the possibility to model numerous autonomous heterogeneous agents, whose behaviors are specified by certain rules. Using ABMs, it becomes possible to model largescale natural or human-made systems (Ballot et al. 2015; Macal and North 2010) and to observe the collective effects of agents' behaviors and interactions. In economic models, equilibrium theories with strongly simplifying assumptions-like rational, homogeneous agents are no longer a limitation to research if ABMs are applied (Macal and North 2010).

Although ABMs have found their justified role in academic research, the implementation of ABMs for crowdfunding platforms in academic literature is surprisingly scarce. Research has mainly engaged in mathematical models (e.g., Alaei et al. 2016; Chang 2016) so far. However, such models are disadvantageous when modeling the complex interplay of numerous agents on crowdfunding platforms. Thoroughly reviewing the literature on crowdfunding, we have discovered only two agent-based approaches. Yang et al. (2016) model the interactions among initiators, funders, and the crowdfunding platform-considering the dynamic process of crowdfunding. However, individuals' preferences and the decision-making are modeled rather rudimentary by pure random variables and do not regard specific characteristics of projects. Although funders are described as heterogeneous, they are homogeneous in terms of investment diversification. Lee et al. (2016) develop a basic ABM to test different methods of distributing donations. Therefore, they determine state variables based on data from different actual crowdfunding platforms. However, the decision of funders which project to support is completely randomly generated and is —again—not based on projects' characteristics. As a consequence, both models do not cover the important feature of funders' decision-making and a discussion of how to model agents' decision behavior more realistically is missing. We go further and propose an advanced ABM that covers a more realistically simulated decision-making behavior of agents while we also provide a theoretical foundation for our model.

\subsection{Methodology}

\subsubsection{Theoretical background for the decision-making behavior of agents}

In the field of crowdfunding research, several theoretical considerations play important roles in order to explain the diverse phenomena observed. Often, research finds valuable support from theories of domains like psychology or finance for explaining these phenomena. For example, Zhang and Liu (2012) describe the herding effect of funding behavior. This effect has been previously discussed in the context of other financial topics as well as psychology (e.g., Olsen 1996; Prechter 2001). 
There are further effects, that have been discussed in the context of crowdfunding and which are quite well established in the domain of psychology. Another example is the bystander effect (Fischer et al. 2011; Latan and Nida 1981). This effect leads to funders expecting that others will help so that they themselves do not engage in funding (Kuppuswamy and Bayus 2013). Furthermore, we find the Matthew effect (Merton 1968). Following this effect, funders especially support projects of those founders who reveal a history of many successfully funded projects (Koch 2016; Zvilichovsky et al. 2015). So far, research on crowdfunding has brought forth several of such connections to established theories. Thus, these theories also become highly relevant when it comes to developing a simulation model that needs to regard certain effects. However, we constrain ourselves to these most important effects for our ABM and refer to the literature that mentions further effects and theories (Koch 2017; Moritz and Block 2016).

These aforementioned theoretical considerations are important for simulating the diverse influencing effects on funding decision-making and, thus, for the fine tuning of agent-based models. However, of much more fundamental importance is the decision-making process itself. In line with the theoretical approach of utility maximization, it can be expected that better rewards lead to higher utility of the funders. Consequently, we can expect that better rewards of a crowdfunding campaign will attract funders. However, the real quality of rewards is hidden and the funder estimates the expected utility. The approach of subjective expected utility (Savage 1972) considers such personal perspectives and explains that decision behavior is subject to both a personal utility function and a personal probability distribution of a specific consequence of a decision. Besides benefits of rewards, further effects, like aspects of altruism (e.g., Bretschneider et al. 2014) or herding effects (Zhang and Liu 2012), play an important role in crowdfunding. Nevertheless, it is difficult to match immaterial benefits to certain levels of utility or to find perfect personal utility functions embracing herding effects-although the approach of utility maximization would theoretically allow to do so. Obviously, the classic utility maximization approach has a strong focus on this match of certain levels of utility to decisions and their outcomes-but it does not leave much space for other, e.g., psychological, explanations of decisions beyond the utility framework. In self-determination theory (SDT), the focus is put on the psychological explanations for decisions. Research has pointed out that self-determination theory is highly valuable for describing decisions, actions, and behaviors of human individuals (e.g., Deci and Ryan 2012; Vansteenkiste et al. 2010). In particular, this theory can be defined as "an approach to human motivation and personality that uses traditional empirical methods while employing an organismic meta-theory that highlights the importance of humans' evolved inner resources for personality development and behavioral self-regulation" (Ryan et al. 1997; Ryan and Deci 2000). "Self-determination theory is a macro-theory of human motivation, emotion, and personality" (Vansteenkiste et al. 2010). This macro-theory embraces five mini-theories which are intertwined and which complement each other-but these mini-theories also have certain distinct foci. These mini-theories are: (1) cognitive evaluation theory, (2) organismic integration theory, (3) causality orientations theory, (4) basic needs theory, and (5) goal content theory (Vansteenkiste et al. 2010). 
Some literature concerning ABMs refers to SDT as a valuable theory in the field (e.g., García-Magariño et al. 2016; Keller 2008; Sharpanskykh and Haest 2015). Also research on crowdfunding has discovered this theory as a fundament for explaining behavior (Allison et al. 2014; Zhang 2004). However, we could not find any research in this context that engages more with explaining individuals' behavior or aligning agent-based models to this theory. Consequently, this theory has been used mainly as a theoretical rationale rather than as foundation for ABM development. We deem it important at least to control whether the ABMs proposed regard the main principles derived from self-determination theory. Thus, in the following, we firstly present the five mini-theories of SDT (Deci and Ryan 2012) and, secondly, derive five basic principles concerning individuals' decision-making behavior which an agent-based model could possibly entail. These principles also help to better describe the decision-making behavior of agents in the context of ABM development and presentation. We emphasize that an ABM has not necessarily to rigorously fulfill all these principles since simplifications are fundamental for ABMs. However, we advise to well consider these principles when reasoning about the design of agents' decision-making behavior.

(i) Cognitive evaluation theory (CET) "was built from research on the dynamic interplay between external events (e.g., rewards, choice) and people's task interest or enjoyment (i.e., intrinsic motivation)" (Vansteenkiste et al. 2010). Specifically, this theory deals with the "effects of social environment on intrinsic motivation" (Deci and Ryan 2012). On the one hand, intrinsic motivations "manifest as engagement in curiosity-based behaviors" (Vansteenkiste et al. 2010) and lead to actions "due to psychological gains" (Allison et al. 2014) like helping or supporting others. On the other hand, extrinsic motivations drive individuals to perform actions in order to obtain some kind of "desired consequence such as tangible rewards or to avoid a threatened punishment" (Deci and Ryan 2000). CET implies that there are certain contingencies between both types of motivations that finally lead to certain behavior. Principle 1: Agents' decision-making regards intrinsic as well as extrinsic motivation.

(ii) Organismic integration theory (OIT) concentrates on extrinsic motivation as a driver of actions (Vansteenkiste et al. 2010). Specifically, it is argued that extrinsic motivation "can vary in the degree to which it is experienced as autonomous versus controlled and, thus, suggested that different types of [extrinsic motivation] can be distinguished" (Vansteenkiste et al. 2010). Moreover, this theory integrates the process of internalization, which "involves endorsing the value of extrinsically motivated behaviors (Ryan and Deci 2000) and is critical for the self-initiation and maintenance of socially important, yet non-intrinsically motivated, behaviors" (Vansteenkiste et al. 2010). Principle 2: Agents' actions are driven and influenced by multi-faceted aspects of extrinsic motivation.

(iii) Causality orientations theory (COT) focuses on "individual differences in global motivational orientations" (Vansteenkiste et al. 2010). The orientations entailed by this theory are autonomy orientation, control orientation, and impersonal 
orientation (Deci and Ryan 1987) and "each of the three causality orientations exists to varying degrees within each of us" (Vansteenkiste et al. 2010). In other words, individuals differ in their orientation and in how they evaluate situations. Principle 3: Agents differ in the way of evaluating things and in decision-making behavior.

(iv) Basic needs theory (BNT) "specifies innate psychological nutriments that are necessary for psychological and physical health, and social wellness" (Vansteenkiste et al. 2010) and encompasses the need for competence, the need for relatedness, and the need for autonomy (Ryan and Deci 2004). "The need for competence leads people to seek challenges that are optimal for their capacities and to persistently attempt to maintain and enhance those skills and capacities through activity" (Ryan and Deci 2004). The need for relatedness reflects "the tendency to connect with and be integral to and accepted by others". And, finally, regarding the need for autonomy, individuals strive to "experience their behavior as an expression of the self, such that, even when actions are influenced by outside sources, the actors concur with those influences, feeling both initiative and value with regard to them" (Vansteenkiste et al. 2010). Principle 4: Agents pursue acting and deciding competently, socially connected, and autonomously.

(v) Goal content theory (GCT) examines the "different types (intrinsic and extrinsic) of life goals, or aspirations, that people pursue" (Vansteenkiste et al. 2010) and "the effects of different goal contents on well-being and performance" (Deci and Ryan 2012). However, "not all goals are created equal" (Ryan et al. 1996; Vansteenkiste et al. 2010) and, thus, the goals are "likely to have differential relations to physical, social, and psychological health" (Vansteenkiste et al. 2010). Principle 5: Agents are satisfied differently by actions performed and outcomes received.

We like to add that —of course-simulated agents do not develop a true feeling of happiness. However, underlying functions and algorithms are able to model certain reactions to specific situations and environmental conditions. Consequently, in agent-based models, we must not see these principles from a pure psychological perspective but in a transferred and much more technically constrained manner. We come back to these five principles in the section of design concepts (Sect. 3.3.4) used in the model and discuss these respective implications in the context of our ABM.

\subsubsection{Methodological framework}

Since the implementation of ABMs is challenging, research has already engaged with the questions of how ABMs are optimally developed and described. For the development of ABMs, Nikolic and Ghorbani (2011) propose to follow the steps of system analysis, model design and detailed design, software implementation, and model evaluation. While Nikolic and Ghorbani (2011) concentrate on a methodological framework for developing ABMs, Grimm et al. (2006) focus on the optimal description of ABMs. They propose the so-called ODD protocol for describing ABMs. This framework consists of an overview (ODDD), the 


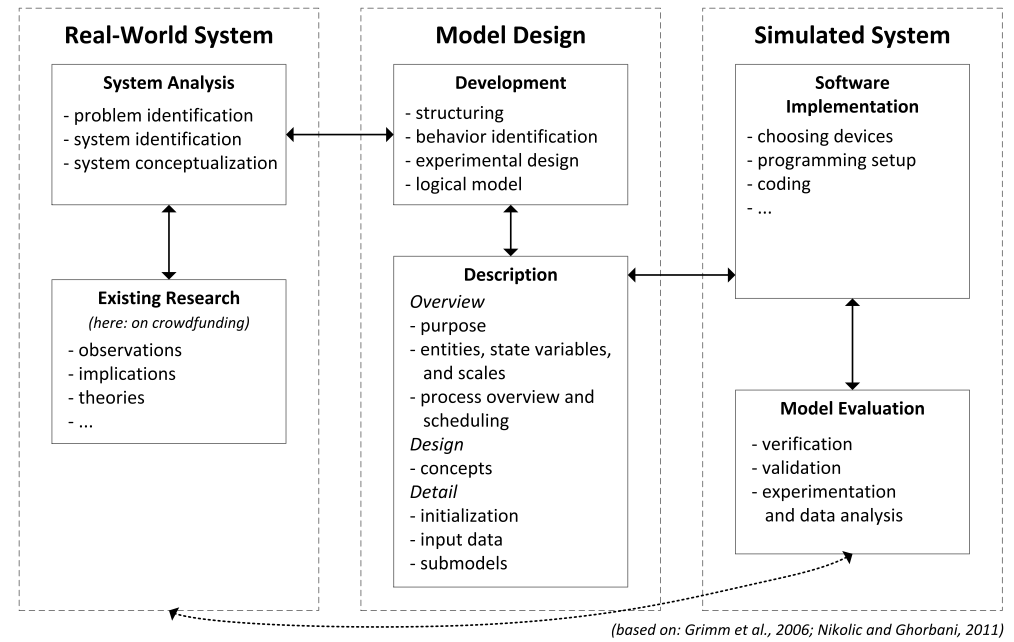

Fig. 1 Framework for developing agent-based models

design concepts (ODD), and the specific details of the model (ODD). The original ODD protocol was updated by Grimm et al. (2010) and the usage of the protocol was clarified by Grimm et al. (2020). Developing our ABM, we apply and regard both guidelines, the methodological framework of Nikolic and Ghorbani (2011) and the latest version of the ODD protocol, combining them to a comprehensive framework which is depicted in Fig. 1.

In a first step, a system analysis (Sect. 3.2) must be performed regarding the real-world system-which is the crowdfunding platform in our case. At this point, we emphasize that existing research is a valuable source of important hints and necessary requirements that need to be regarded. It is true that the system analysis is in the area of ABM developers' responsibility; however, it is important and fruitful to consider existing work in this field. Based on the system analysis, the model design (Sect. 3.3) follows. Here, we include the logical elements of the detailed design regarding the development of our model. Furthermore, we regard the advice for describing ABMs given by Grimm et al. (2010) and describe our model using the ODD protocol. In this regard, we consider the purpose of the model (Sect. 3.3.1), the entities, state variables, and scales (Sect. 3.3.2), the process overview and scheduling (Sect. 3.3.3), the design concepts used (Sect. 3.3.4), initialization and input (Sect. 3.3.5), and submodels (Sect. 3.3.6). We do not detail on the step of software implementation as this does not contribute to the understanding of our ABM approach. Next, the model must undergo a model evaluation (Sect. 3.4). In this section, we also include the experimental design of the detailed design as stated in Nikolic and Ghorbani (2011). At this point, we perform a validation and verification of our model and compare the ABMs' results to the real-world system (Sect. 3.4.1). Then, we conduct a policy experiment to address our research question of whether a funding 
redistribution mechanism is able to improve overall funding results on a crowdfunding platform (Sect. 3.4.2).

\subsection{System analysis}

The complexity of a crowdfunding platform mainly arises out of the big number of agents and objects involved and their multi-faceted interactions and behaviors. In crowdfunding, we can identify numerous stakeholders concerned (Koch 2017). The main agents involved are platform operators, project initiators, and funders. The operators determine platform parameters and the funding mechanism. While initiators decide on how to design the crowdfunding campaigns, funders screen these campaigns and decide for funding certain projects or not. Moreover, social connections play an important role. The first funding contributions are usually made by family members and friends who often act because of "social obligation" (Agrawal et al. 2015). All other funders concentrate on information used for the presentation of projects and to the amount of funding that has already been reached (Agrawal et al. 2015; Koch and Siering 2015; Kuppuswamy and Bayus 2013; Mollick 2014; Zhang and Liu 2012). We emphasize that further effects, like the visibility of project presentations on the platform, advertising in social media, convincing comments, and update posts also play certain roles (Li and Duan 2014). For details, we refer to the literature on crowdfunding in general (e.g., Beaulieu et al. 2015) and on specific effects, such as the herding effect (Zhang and Liu 2012) or the bystander effect (Kuppuswamy and Bayus 2013). When developing an ABM, simplifications are needed to handle the complexity. The decision of which effects are explicitly regarded in the model is described in the following section, in which we describe our whole model according to the ODD protocol (Grimm et al. 2010).

\subsection{Model design}

\subsubsection{Purpose}

The goal of this paper is to address the question of how externalities of overfunded projects on crowdfunding platforms can be internalized to contribute to the discussion on how crowdfunding serves best all of its stakeholders. In order to address this question, we follow economic theory regarding the internalization of externalities and develop different countermeasures to tackle the problem of massive overfunding on crowdfunding platforms. In particular, we develop a funding redistribution mechanisms that imposes a tax on overfunding and redistributes the tax revenues to other valuable projects and compare different configurations of this mechanism to a baseline model that allows overfunding without imposing a tax and one adjusted model that bans overfunding completely. Therefore, the purpose and goal of our model is twofold: first, in order to analyze countermeasures for externalities on crowdfunding platforms, our baseline model-which 
does not apply any countermeasures - needs to replicate a real-world crowdfunding platform and it's participants' funding behavior as close as possible. Second, the model and in particular the funding behavior of the simulated platform participants need to be easily adjustable, so that possible countermeasures can be implemented in the model and are considered in the participants' funding decision-making mechanism.

\subsubsection{Entities, state variables, and scales}

In our study, we concentrate on reward-based crowdfunding since we calibrate our model using original data from a reward-based crowdfunding platform. Moreover, we consider an all-or-nothing model because, here, failing to reach the funding goal has more serious consequences-compared to the keep-it-all model. To replicate the respective crowdfunding platform, we simulate the three main parties participating in the funding process: the crowdfunding platform itself, the campaign initiators, and the funders. These three parties represent the simulated entities in our ABM. Simply explained, the relationship between the three entities is as follows: on the platform, campaign initiators can start new crowdfunding campaigns and present them to the group of funders. Funders observe multiple campaigns, evaluate them, and decide whether to support them by funding or not. The platform manages the campaigns and delivers information about ongoing projects to the funders.

The ABM simulates a specific time period, i.e., a pre-defined number of days. Since crowdfunding platforms do not only run on business days, each simulated entity performs a daily routine every day in the pre-defined time period (which is described in detail in the following section). Hence, dynamic state variables of all entities change for each simulation day. Hereby, the entities are modeled as follows:

Crowdfunding campaigns In our model, we do not explicitly simulate campaign initiator agents, but simply model the pool of projects that the funders choose from. Campaign initiators would only be needed if they would reveal active behavior or if their activities would be important to be tracked. Since we focus on the funding behavior of the funders, we do not need to simulate the initiators. Hence, the campaigns reveal no actions or behaviors but certain characteristics and parameters. The funding success of a campaign depends on these properties and the connected decision-making of the funders. The campaigns' properties can be divided into three categories: (1) the first category encompasses the parameters that describe the project, i.e., the number of videos, the number of pictures, and the length of the textual description (descriptive parameters). Such aspects that are revealed by actual campaigns on platforms are explicitly modeled. These parameters do not change over time and are evaluated qualitatively similar by each funder. (2) The second category consists of properties that change over time and are, thus, evaluated differently according to when they are regarded (dynamic parameters). These parameters are the amount of collected funding and the elapsed time of the funding period. Another variable that changes over time is added when taxes are enabled. Then, for each project that is overfunded, the collected taxes of the current day are temporarily stored within the respective instance of the campaign. (3) The third category contains 
properties that are set by project start and are differently evaluated by the funders (parameters of taste). These are the project category and a unique parameter of taste. Transferred to the real world, this simulates, e.g., that a funder prefers projects concerning the category of music-but only a certain kind of music. To include the effect of initial funding by family and friends, projects can be considered for an initial funding within a pre-defined number of days from campaign start.

Crowdfunding platform The main task of the crowdfunding platform is to manage the currently ongoing campaigns and provide information about the campaigns to the funders. Consequently, the platform serves as intermediary between campaign initiators and funders. Furthermore, apart from the baseline model, the platform is responsible for collecting and redistributing taxes. The platform's properties can be divided into two groups: (1) parameters that do not change over time and adjust the market mechanism of the platform. These parameters are used to model the overfunding countermeasures and represent different tax applications or a binary variable that bans overfunding on the platform. (2) Properties that change over time. These are a vector of the currently active campaigns (including all information for each campaign) and - apart from the baseline model - the amount of taxes collected on a specific simulation day.

Funders In our opinion, funders' decision-making behavior constitutes the core of the system. Funders decide whether to support a campaign or not based on the properties of the observed campaigns and the modeled decision function. In our model, a funder can be active or inactive-like on real platforms. In the first case, the agent takes part in funding; in the second case, there are no funding actions. This state can change every simulation day and the probability of a funder to be active varies among individual agents. Furthermore, a funder reveals several static properties, which are assigned at the beginning of the simulation. These properties encompass the likelihood of a funder to be active, the number of projects to be observed, and the likelihood to participate in an initial funding. In order to simulate heterogeneous funders, the model attributes preferences for certain project categories and an individual preference parameter to each funder. If a funder's preference parameter is close to a campaign's taste parameter, the funder values the campaign higher.

\subsubsection{Process overview and scheduling}

As described above, the ABM models time as a pre-defined number of days and each entity in the simulation performs a daily routine for every day in this time period. To control this process and the schedule of the ABM, we implement an observer class that is responsible for setting up and running the simulation. Each day of the simulation the following schedule applies: first, based on a pre-defined distribution function, a random sample defines the number of new campaigns initialized on the current simulation day. Second, each campaign performs its daily routine. As described above, the campaigns in our model do not perform any actions. Therefore, the only task of a campaign is - when taxes are enabled - to forward the taxes collected in case of overfunding to the crowdfunding platform. Third, the simulated 


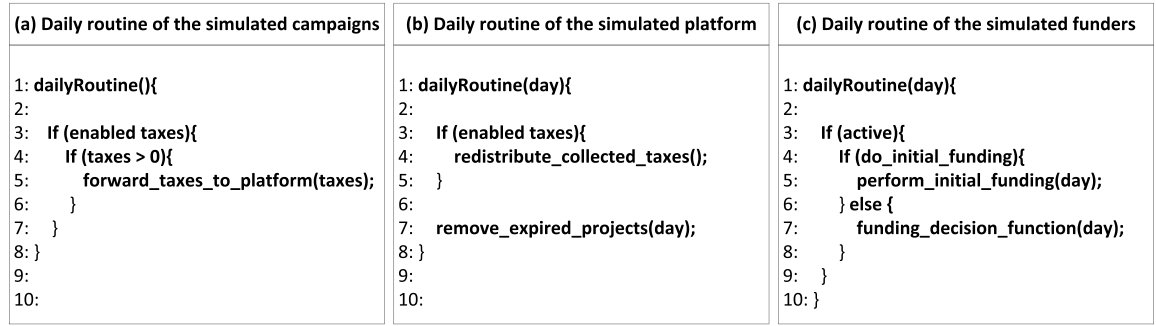

Fig. 2 Pseudocode of the daily routines for each simulated entity

crowdfunding platform performs its daily routine. If taxes are enabled, the platform redistributes the received taxes of the previous day to those projects that have closely missed their funding goal, starting with the project closest to its goal. Thereby, the funding level relative to the project goal that projects have reached serves as a proxy for quality in order to avoid funding of low-quality projects. The platform then removes expired projects from the vector of active projects. Fourth, each simulated funder performs their daily routine. For each funder, it is determined whether the funder becomes active or not. Then, if a funder is active, another random process determines whether a funder makes an initial funding or a normal funding. In case of an initial funding, the funder randomly draws a project independently from its valuation and funds it. In the case of a normal funding, a funder's choice of supporting projects is determined by a decision mechanism considering the funder's individual characteristics and the observed projects' properties. Each funder supports a pre-defined number of projects based on the resulting vector of evaluated projects. Figure 2 illustrates the daily routine for each simulated entity using pseudo code. We provide detailed information regarding the entities' different mechanisms in the submodels section.

For a better understanding of the relations between the different simulated entities, we include the class structure of the most important classes and a selection of their key parameters and functions in Fig. 5 in Appendix 1. While the observer class implements and initializes the environment of the simulation and manages the simulation process, all instances of the other classes perform their daily routines as described above.

\subsubsection{Design concepts}

To classify the introduced ABM within complex adaptive systems and to check whether certain design parameters are implemented, we follow Grimm et al. (2010) and discuss the design concept of our model. Thereby, we discuss each of the eleven proposed design concepts:

(1) Basic principles: In our model, the main focus is on the complex decision-making behavior of funders. Thus, we explicitly align this decision-making concept used in our model to self-determination theory using the five principles derived in 
Sect. 3.1.1. We model the funders' behavior according to Principle 1 as they reveal both intrinsic as well as extrinsic behavior. Funders decide to support projects by an initial funding without regarding their potential economic benefits (intrinsic funding motivation) and they also engage in finding the best funding opportunities as they desire, for example, the promising rewards (extrinsic funding motivation). Moreover, funders reveal a multi-faceted way of evaluating projects following their extrinsic motivation (Principle 2). Thereby, they do not only consider single aspects for funding decisions but a long vector of different aspects. Agents have different favorite projects (Principle 5) and, thus, differ in their decision-making. As a consequence, our model simulates agents that are heterogeneous concerning their decision behavior (Principle 3). Finally, agents decide on their own and do not follow prescriptions. They also reveal social ties as they partly follow others concerning their funding decision (herding effect) and engage in initial funding to support family members or friends (Principle 4). Conclusively, we argue that the decision-making behavior simulated in our ABM is in line with the main principles that can be derived from self-determination theory. Thus, we conclude that the design of the decision-making behavior that we propose in the subsequent section reveals important aspects of the behavior of actual funders in the real-world crowdfunding platforms.

(2) Emergence: Bonabeau (2002) describes emergence as the result of the interaction of different agents in a system, where the result is more valuable than the components. In our model, the funding outcomes of the campaigns are such emergent phenomena because they are the key result of a complex interaction process of all entities involved and the decision behavior of the funders in the simulation.

(3) Adaption: The agents of our model are limited concerning their adapting behavior. As described above, we do not consider any adapting behavior or actions for campaigns or the simulated crowdfunding platform. We rather focus on the decision making behavior of funders. Therefore, the funders adapt their funding choices to the campaigns available at the moment of evaluation. Hereby, funders evaluate different properties of the observed campaigns and compare them when deciding whether or not to support a project. Furthermore, funders are adaptive to changes in their environment. For instance, when the crowdfunding platform changes its market mechanism and applies a tax on overfunding (or bans overfunding), funders adjust their decision behavior in regard to the respective change.

(4) Objectives: Since we only consider adaptive behavior for funders, these represent the only entity that reveal objectives regarding their decision function. In our model, funders actively optimize their funding choice following their decision-making behavior and engage in supporting the best rated campaigns according to their individual evaluations. Hereby, the objective of a funder is to make the best possible funding decision based on the information observed. As described in Sect. 3.3.2, this decision function is based on static, dynamic, and individual characteristics considered for each observed campaign. Moreover, a funder decides not to fund a campaign, if it is evaluated below a specific decision threshold. Instead, the funder does an alternative investment outside of the platform or consumes the money. 
(5) Learning: In our model, we do not consider any learning behavior for our simulated entities. Therefore, agents do not adjust their behavior based on experience.

(6) Prediction: Regarding the funding decision behavior of funders and their general objective of making the best possible funding decision, funders evaluate in their decision making which campaign is of highest value for them. Thereby, if a project did not yet reach its funding goal, one aspect that is important for the funding decision is to anticipate the probability of a project to reach its funding goal. In our model, a funder evaluates different characteristics of the observed campaigns, that are related to future campaign success. First, the static properties of the campaigns which are evaluated equally by each funder. Second, the dynamic properties representing elapsed time and collected funding. Hereby, funders are more likely to support a campaign the more time remains (bystander effect) and the more funding is pledged (herding effect) (Li and Duan 2014).

(7) Sensing: As described above, funders consider ("sense") different static, dynamic, and individual properties of the observed campaigns as well as the properties of the platform's market mechanism within their funding decision.

(8) Interaction: In our model, we consider interactions between the different simulated entities. Projects are initialized on the platform, the platform forwards a list of projects to the funders, and the funders support the projects on the platform. We do not consider direct interactions within the different entities. However, funders reveal indirect interactions within their decision mechanism by observing how much funding other funders have provided for the observed campaigns and especially supporting campaigns that have been funded before (herding effect).

(9) Stochasticity: We apply different stochastic processes in our model. Regarding the campaigns, properties are assigned based on random samples from real-world frequency distributions. Furthermore, the number of new campaigns per day and certain parameters that determine the funders' characteristics and their daily routine are modeled based on random and partly random processes. These are the individual preference factor, the probability of a funder being active, the probability of a funder making an initial funding, the sample of campaigns observed, and the funding amount.

(10) Collectives: Agents in our model do not form any organized collective or group and, therefore, perform independently their individual daily routine.

(11) Observation: For calibrating, testing, and evaluating the results of the simulation, we collect data for each simulated day. Hereby, all information regarding the campaigns that reach the end of their funding period are collected and saved. This information comprises the campaigns' properties and the received funding. 


\subsubsection{Initialization and input}

Apart from running the simulation, the observer class is also responsible for initializing the $\mathrm{ABM}$ and importing the parameter configuration. The simulation starts with reading a configuration file for initializing and reading the data set used for generating the distributions. Then, the funders are generated and the simulation starts. On each day campaigns are generated and all agents perform their daily routine as described above. Before the generated data of the simulation is saved, the program needs to be initialized. For this reason, the model is run 120 days without storing the data because right at the beginning there are only few projects active. After 120 simulation days, the model is initialized and the data is saved for the analysis.

To configure our ABM, we use data and different characteristics observed from real-world crowdfunding platforms. Furthermore, since some properties of funders are hard to observe, we have to make assumptions regarding their decision-making process and need to optimize their decision behavior when calibrating the ABM.

After initialization, we run our model for a full simulation year, i.e., 360 simulation days. Each day, a specific number of projects is initialized on the platform. Since we do not know the distribution of newly initialized projects per day, but can approximate the average number of projects per day based on statistics provided on the kickstarter homepage, ${ }^{1}$ we use a Poisson distribution with $\lambda=170$ representing the average number of new projects per day until the end of 2014 (matching the respective year of observations in our data set).

The initialized campaigns in our model reveal realistic funding periods following a frequency distribution drawn from a real data set of a crowdfunding platform. Furthermore, we draw the funding goal, the number of pictures, the text length of project descriptions, the number of videos, and project categories using discrete frequency distributions derived from our data set. All data for the distributions that we use is derived from kickstarter, one of the largest crowdfunding platforms. Our data set comprises a random sample of 32,000 campaigns in the time period of November 2013 until November 2014. To avoid outliers within our simulation, we cut observations above the 99th percentile for each parameter derived from the data set. We provide descriptive statistics for our data set in Tables 2 and 3 in Appendix 2. Finally, the projects' unique parameters of taste are randomly drawn following a uniform distribution of the interval $[0,1]$. Since we already consider a certain dimension of taste by assigning the campaigns' categories based on a real world distribution, we consider a uniform distribution and assume that taste is equally distributed within the categories.

On the platform, a pre-defined number of funders is registered. Since in the real world funders can be single or multiple funders and we only consider multiple funders in our model, we calibrate the number of funders when optimizing our model. A funder gets active with an individual probability which is drawn from a uniform distribution of the interval $[0,1]$ being a standard choice for modeling random processes in simulations where the underlying distribution is unknown (Law 2015). Based on a pre-defined

\footnotetext{
1 https://www.kickstarter.com/help/stats?ref=global-footer.
} 


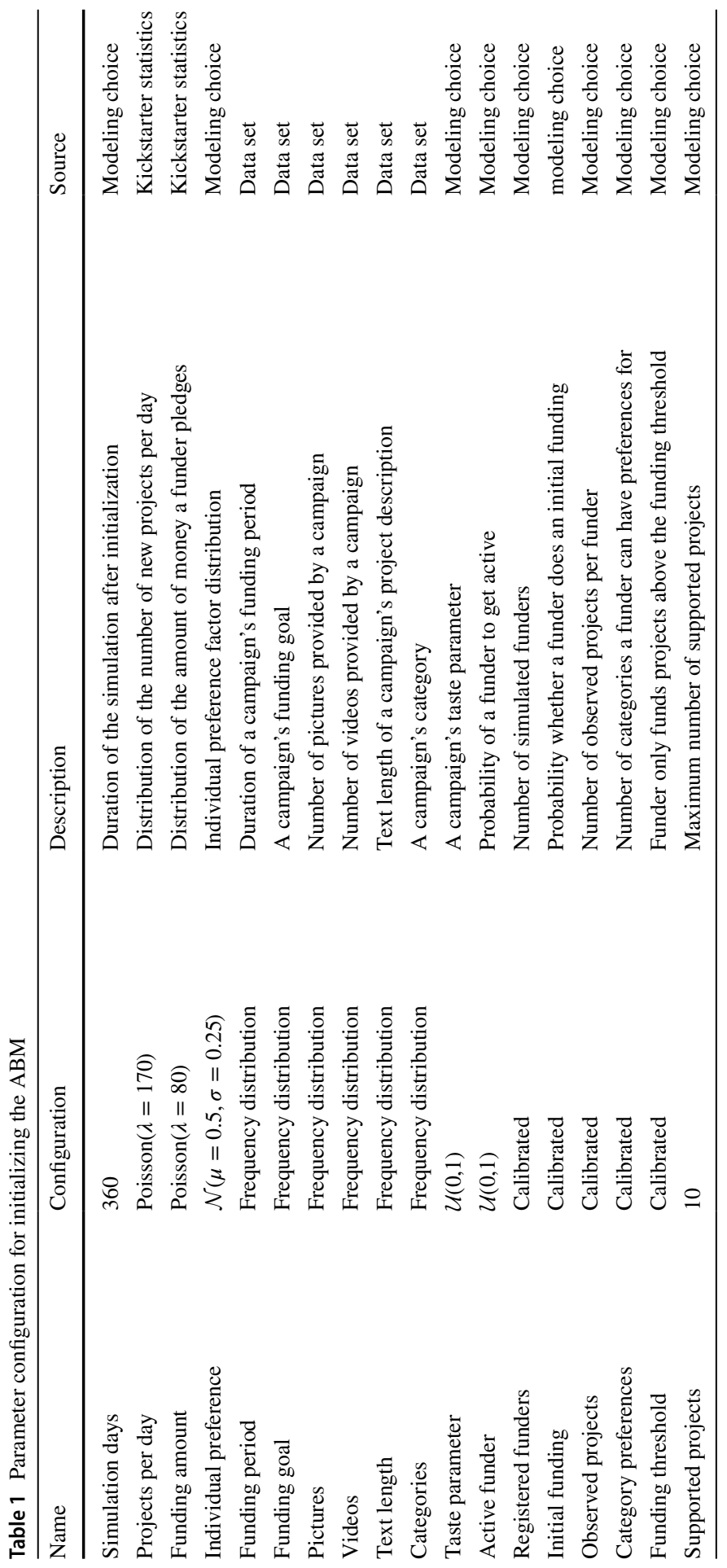


probability it is determined whether a funder does an initial funding or a normal funding. A project can receive an initial funding at a maximum of three days after its foundation. Thereby, we consider the following relationship: on average a project has $x$ initial pledges. With on average 40,000 pledges per day on the platform, and on average 170 new projects per day, the probability would be $P($ initial $)=\frac{x \times 170}{40,000}$. We optimize the number of initial pledges $x$ when calibrating our model. We further optimize the size of the random subset of projects each funder observes when making their funding decision and the number of categories a funder can have preferences for. The individual preference parameters of funders are drawn from a normal distribution $(\mu=0.5$, $\sigma=0.25$ ) and are winsorized so that if the value of a sample is below 0 or above 1 , a value of 0 or respectively 1 is assigned. Since we simulate a much larger number of funders than campaigns, we assume that different from campaign initiators, taste is normally distributed among funders. Like for the number of projects per day, we do not know the distribution of the amounts funded. Therefore, we use the average funding amount based on the kickstarter statistics and draw the amount of money a funder pledges when supporting a project from a Poisson distribution $(\lambda=80)$. These values constitute the budget constraints for funding. If there are no projects valued above or equal to a certain threshold, a funder chooses an alternative investment opportunity outside the platform. We optimize this threshold when calibrating our model. Based on the campaigns observed and the funding threshold, funders support a maximum of 10 projects.

All parameters are based on real-world data or are calibrated to model reality properly. The parameter configuration is summarized in Table 1. We provide more details on the model calibration in Sect. 3.4.

\subsubsection{Submodels}

As described in Sect. 3.3.3, the simulated entities in our ABM perform their daily routine each day of the simulation. While the daily routines of the simulated campaigns and the platform are straight-forward, the daily routine and in particular the funding decision mechanism of the funders-which is the core decision model of our ABMneeds to be described more in detail.

Although the funding decision-making behavior is of central importance, previous $\mathrm{ABM}$ research has disregarded these behavioral aspects. Consequently, we propose a decision-making mechanism which is based on a method that is already well-established in research. In a first step, funders regard a certain number of randomly drawn projects that they could potentially support. This simulates the fact that a funder is not able to screen all projects but will only discover a limited number of projects (limited awareness). For example, some funders screen the projects for certain topics or use a keyword search. However, this limitation of funders' awareness can be adapted and means no restriction for the model. Next, there are two funding principles. First, for each time a funder becomes active, a random variable is drawn that determines whether the funder makes a normal or an initial funding. In case of an initial funding, the funder supports a randomly drawn project that was just started on the platform. This simulates an initial funding that is made by family members and friends. Such funding 
contributions are mostly independent from quality or descriptive parameters (Agrawal et al. 2015). However, this type of funding is less frequent and is optimized when calibrating the model. In case of a normal funding, campaigns' parameters are explicitly regarded. Here, we follow the multi-attribute decision-making (MADM) method proposed by Xu (2015). This method uses the ordered weighted averaging (OWA) operator introduced by Yager (1988). The OWA operator regards a vector of $n$ decision-relevant parameters. First, these parameters $a_{k}$ of the vector are ordered by their size. Next, each element $b_{j}$ of the ordered vector is multiplied by a certain predetermined weight $w_{j}$. Following the notation of Fullér (1996), the OWA operator is defined as follows:

$$
\begin{aligned}
F\left(a_{1}, \ldots, a_{k}, \ldots, a_{n}\right)= & \sum_{j=1}^{n} w_{j} b_{j}, \\
& \text { where } b_{j} \text { is the j-th largest element of a } \operatorname{bag}\left\{a_{1}, \ldots, a_{n}\right\}, \\
& \text { and } w=\left(w_{1}, w_{2}, \ldots, w_{n}\right)^{T}, \text { with } w_{i} \in[0,1], 1 \leq i \leq n, \\
& \text { and } \sum_{i=1}^{n} w_{i}=1 .
\end{aligned}
$$

The result can be interpreted as a certain value that is attributed to this set of parameters by a respective funder. Yager (1988) identifies two important concepts of the OWA operator: andness and orness. With a high orness, it is possible that properties can compensate each other. In case of a high andness, there is less compensation. The level of andness/orness results from the vector of weights and is able to imitate individuals' evaluations (Fullér 1996). For our model, we choose the simplest setup of this vector, in which all weights are equal. In order to make the project properties appropriate for using the OWA operator, and according to the MADM method, the properties are normalized on an interval of [0,1]. Based on $\mathrm{Xu}$ (2015), we use the following formulas for normalization:

(i)

$$
\begin{aligned}
& \text { Benefit type (high values preferred): } \quad n_{i}=\frac{a_{i}-\min \left\{a_{1}, \ldots, a_{n}\right\}}{\max \left\{a_{1}, \ldots, a_{n}\right\}-\min \left\{a_{1}, \ldots, a_{n}\right\}}, \\
& \text { Cost type (low values preferred): } \quad n_{i}=\frac{\left.\left.\max \left\{a_{1}, \ldots, a_{n}\right\}\right\} a_{i}, \ldots, a_{n}\right\}}{\max \left\{a_{1}, \ldots, a_{n}\right\}-\min \left\{a_{1}, \ldots, a_{n}\right\}}, \\
& \begin{array}{l}
\text { Fixed type* (values close to a fixed } \quad n_{i}=\frac{\left|a_{i}-\alpha\right|}{\max \left\{\left|a_{i}-\alpha\right|\right\}} . \\
\text { value } \alpha \text { are preferred): }
\end{array}
\end{aligned}
$$

[* Be careful—-there are some issues with the notation used in Xu (2015).]

The parameters of each observed campaign are normalized according to the respective types stated above. Thereby, we use the benefit-type for the following static properties: the number of pictures, the number of videos, and the text length. Here, for instance, the more pictures are used, the more likely is a funding contribution (Koch and Siering 2015). Furthermore, we include a benefit-type vector for the project category. For each category a funder has a preference for, all projects belonging to one of those categories are evaluated with a value of 1 and all other projects with 0 . In the case of individual taste, the fixed type of normalization is used.

Regarding the evaluation of dynamic campaign properties, we explicitly regard the effect of achieved funding (herding effect) and the effect of time lapsed 
(bystander effect). Following Li and Duan (2014), there exists the following relationship: the more time remains and the more money is pledged, the more likely funders support a project. To catch these effects, we use a formula that exactly reveals this behavior: $1-(1-\theta)^{-\log (d)} \in[0,1]$. Here, $d$ is the percentage of time lapsed and $\theta$ is the proportion of the collected money relative to the goal. This parameter is normalized as a benefit-type. If the funding goal is finally reached, we expect that the intrinsic motivation to support a campaign to reach its goal vanishes. Besides the herding effect, there is another effect we observe for campaigns that are close to their funding goal. In our data set, there are less than $0.5 \%$ of observations that received funding above $80 \%$ of their funding goal. Therefore, we expect campaigns to be more attractive the closer they are to their funding goal. To include this effect, we consider a benefit-type vector in the decision function, that evaluates campaigns based on the relative amount received to their funding goal. Within this vector, campaigns that received funding below $80 \%$ of their funding goal and campaigns that are already successfully funded are evaluated with a value of 0 . Another effect that we observe in our data is that overfunding becomes less attractive the more overfunded a project is. To incorporate this effect in the decision function of the funders, we include a cost-type vector and optimize a function that reproduces this effect within the calibration of our model. Hereby, we consider different functional forms and specifications.

Since, apart from the baseline model, we also consider the application of different tax applications in our model, we also consider the tax in the decision function of the funders. In the ABM, the tax is implemented as a cost-type parameter. If the funding goal is reached, the tax $\tau$ is applied. Then, this aspect is evaluated with $1-\alpha \times \tau$ by the funders. $\alpha$ is the parameter that defines how strong funders react to the increased price. In our experiment we choose $\alpha=10$. This parameter allows for later adjustments in case of different platforms and culturally or behavioral different individuals that might reveal different reactions to higher prices.

Finally, the vectors of the normalized parameters are arranged in a decision matrix as proposed by $\mathrm{Xu}$ (2015). Subsequently, the OWA operator is used to evaluate each campaign. Then, the projects are sorted according to the evaluation and the best projects are chosen for funding. In contrast to the ABMs proposed so far, the funding decision-making is no longer purely random but is based on the parameters of the campaigns at choice. Finally, we expect that funders do not fund projects that are valued below a certain threshold. If the considered projects are valued below this threshold, a funder invests into an alternative investment opportunity (or spends the money).

\subsection{Evaluation of the model}

The development of ABMs is no end in itself but is supposed to provide the basis for promising investigation opportunities. Therefore, an ABM needs to be evaluated so that possible flaws or limitations can be discovered and resolved. An important step in the development of ABMs is the verification and validation of the model. The verification addresses the question of whether the model does what it is intended 
to do (Nikolic and Ghorbani 2011). Next, in the validation, it is checked whether "the modeled outcomes correspond with observed reality" (Nikolic and Ghorbani 2011). The fact that ABMs are simplified models of real-world processes demands for certain simplifications. These simplifications, however, must not lead to distortions of models' outcomes. In order to calibrate our model, we choose a basic scenario that allows for comparing funding outcomes to real-world data. If the ABM is able to produce funding outcomes that are similar to actual funding outcomes of existing platforms, the processes implemented in the ABMs are able to imitate the relevant processes. The main advantage of agent-based models is the opportunity to model and analyze complex systems which could not or not easily be captured by pure mathematical calculation, e.g., by applying stochastic equations. Applying simulated scenarios, an ABM can be used for experiments and fulfills two important tasks. First, an ABM can confirm or reject a conjecture. Therefore, some kind of input is given into the system and, finally, a specific output is received that allows for confirming or rejecting the conjecture. In a simple case, this may not bring forth an amazing miracle as the basic coherences are often clear and allow for an educated guess. However, second, the ABM can be used for a sensitivity analysis and for optimization problems. By (systematically) changing the input parameters, the characteristic responses from the system can be analyzed and transformed to new insights about the system. Such inferences are important and of high value for decision situations. These insights can be used for developing rules of thumb or as a basis for managerial decisions. Consequently, the ABM becomes a powerful decision support tool of market engineering that aids, e.g., model design and price determination.

\subsubsection{Calibration, verification, and validation}

Before trusting ABMs' results, literature advises to control for correctness and plausibility. Of course, it is difficult to reconstruct each single step processed in the simulations. However, it is possible to control the overall outcomes. Therefore, for calibrating our $\mathrm{ABM}$, we define certain rules, so that the final $\mathrm{ABM}$ replicates the real-world funding outcomes as good as possible. We follow the literature on calibrating ABMs and apply a simulated method of moments (SMM) approach (McFadden 1989).

In this context, Fagiolo et al. (2019) define output validation as the assessment of "how successfully the simulations' output exhibits the historical behaviors of the real-world target system". As discussed before, we cannot replicate the full historical behavior of a crowdfunding platform. Therefore, we follow Winker et al. (2007), who propose an objective function based on stochastic moments related to stylized facts of the underlying target system to assess the application of agent-based models. For this purpose, we first need to select appropriate moments to contribute to the goal of replicating the real-world target system as good as possible and, then, need to select a weighting function, that adequately measures the distance between the real-world system and the simulation. We, then, minimize this distance based on different parameter configurations.

Since the main purpose of our model is to replicate the funding behavior of funders on crowdfunding platforms, the target of calibrating our model is to optimize 


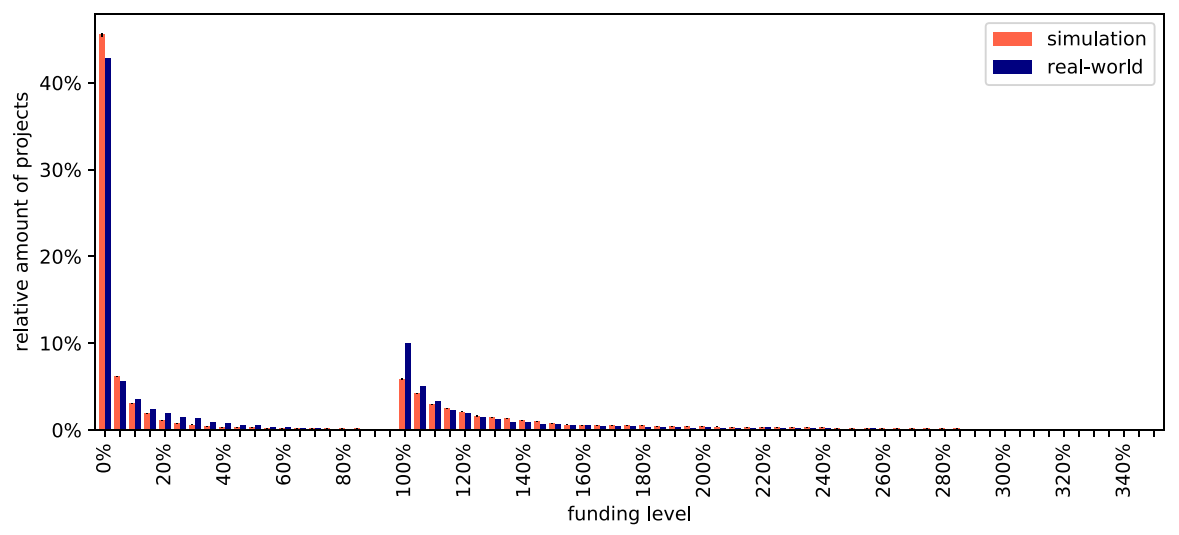

Fig. 3 Resulting distribution of funding outcomes

the emergent funding distribution of the simulation. The crowdfunding literature identifies two characteristic peaks in the distribution of funding outcomes close to $0 \%$ and $100 \%$ of funding (Koch 2016; Kuppuswamy and Bayus 2013; Lu et al. 2014) stating that among "crowdfunded projects, failures happen by large amounts, successes by small amounts" (Mollick 2014). Furthermore, besides the characteristic peaks, both the funding distributions of successfully funded projects and the distribution of unsuccessfully projects reveal characteristic right skews (Koch 2016). We focus on these stylized facts based on the literature to optimize our model. For both of the distributions, we consider the first three stochastic moments (mean, standard deviation, and skewness). Compared to standard approaches only considering the first two moments, we add the third moment because the skewness represents the core characteristic of both distributions. Furthermore, since we consider two distributions that are not independent of each other, we can not simply minimize the distance of the moments, but also need to ensure, that the ratio of successfully funded projects to unsuccessfully projects and the overfunding rate are close to the target system. Therefore, we compute two distance functions: first, we calculate the distance of these two ratios to the target system and second the distance of the distributions' moments to the target system. For calculating the distances to the target system, we use a standard Euclidean distance function. Since the moments may have different scales and moments which are on a higher scale would overshadow moments on lower scales, we normalize each parameters' distance on an interval of $[0,1]$ based on all configurations before calculating the distance functions. To determine the final distance, we add both resulting distances by giving each of the both functions a weight of 0.5. As discussed in Sect. 3.3.5, we optimize different parameters when calibrating our model (see Table 1). We report the whole parameter configuration in Table 4 in Appendix 3.

Since we include several random processes within our model, before comparing and analyzing the results of the different configurations, we perform a Monte Carlo simulation with 50 runs per parameter configuration to eliminate the impact of particular random seeds. We, then, use the median values of the emerging distributions' 
characteristics (ratio of successfully funded projects to unsuccessfully projects, overfunding rate, and moments of the distributions) to find the best configuration for our model.

Figure 3 depicts the distribution of funding outcomes for the best configuration of our model for the baseline scenario. For reasons of clarity, we use intervals of $5 \%$. The reported values represent the median values of the different Monte Carlo simulation runs for each interval. We further add the $95 \%$ confidence interval for each interval of the simulation data showing that there is not much variation between the different iterations of the Monte Carlo simulation.

Comparing the distribution in this figure to the distribution of the real-world data as well as those that have been published in other studies based on authentic data from platforms (Koch 2016; Kuppuswamy and Bayus 2013; Lu et al. 2014; Mollick 2014), we can see that the funding behavior modeled in our ABM reveals a similar distribution. We only observe a slightly higher peak around a funding level of $0 \%$ and a slightly lower peak around $100 \%$. The good fit can also be observed when comparing the moments of both distributions. Here, the success rate $(39.49 \%)$ as well as the first three moments of the emerging distribution of not successfully funded projects $(\mu=5.62 \%, \sigma=13.13 \%$, skewness $=$ 3.89 ) show a good fit to the real-world data (success rate $=37.50 \%, \mu=7.34 \%$, $\sigma=13.97 \%$, skewness $=2.67$ ). The slightly lower mean value can be explained by the slightly higher peak at the funding level of $0 \%$. Furthermore, while the moments of the distribution of the successfully (and overfunded) campaigns $(\mu=234.73 \%, \sigma=327.18 \%$, skewness $=4.65)$ show that projects in the simulation on average are more overfunded than projects in our data set $(\mu=179.27 \%$, $\sigma=211.57 \%$, skewness $=6.67)$, the overfunding rate $(30.88 \%$ vs. $48.90 \%)$ suggest a higher share of overfunding in the real-world data. One explanation for this results could be, that we only model multiple funders and since the contributions of single-time funders are missing in our model, campaigns that receive the most overfunding according to the real-world receive a little bit less funding in our simulation. However, it is not important to exactly replicate the data observed from an actual crowdfunding platform, but to incorporate the key mechanisms of the decision behavior of funders in the model. The distributions exhibit an overall good fit to the real-world data and show that the model is able to reasonably replicate the key characteristics of the funding distribution of real-world crowdfunding platforms. The results of the best model configuration are summarized in Table 6 in Appendix 3.

To further show that the resulting distribution is robust when marginally changing the parameter configuration and to verify that the emergent distribution is not only an artifact of a particular initialization, we perform several robustness checks and report the results in Tables 5 and 6 as well as Fig. 6 in Appendix 3. The results show, that the emergent distributions only marginally change compared to the above determined best configuration and still feature the characteristics of real-world funding distributions. Hence, the ABM is robust to marginal changes in the parametrization. The results also indicate, that the parameters configuring the observed projects and the decision threshold are the most sensitive parameters because they have a huge impact on the decision-making mechanism 
of funders. Therefore, when calibrating the ABM these parameters need to be chosen carefully.

We conclude that the ABM proposed is able to reproduce comparable funding results to those of actual crowdfunding platforms and, thus, can be used to perform policy experiments in order to obtain first indications how changes in the market design affect the market dynamics on crowdfunding platforms. We use our best setup as a starting point for analyzing the effect of introducing different tax mechanism in order to improve overall funding results within our policy experiment.

\subsubsection{Policy experiment: applying a tax to overfunding}

After having verified that our agent-based model delivers suitable results in the baseline scenario, we conduct a policy experiment and address our research question by analyzing whether introducing a tax on crowdfunding platforms helps to internalize the negative externalities of overfunding. As a practical alignment, we follow the four steps (i-iv) proposed by Gupta and Prakash (1993) for the process of internalizing externalities (Sect. 2.2). (1) Research analyses have recognized negative externalities resulting from overfunded projects on crowdfunding platforms (Kim et al. 2016; Liu et al. 2015). (2) However, not the projects or initiators are the perpetrators that cause the negative externalities, but the funders who are the active deciders and choose to concentrate on blockbuster projects. By this focus, some projects become more visible and overshadow other projects. The victims of such behavior are projects that reveal less funding but also the funders of these projects because their favored projects are not completed. (3) We argue that funding is beneficial when it helps a project to reach its funding goal, i.e., the required amount of funding for the project. Funding that succeeds this goal is mainly provided because funders are massively attracted by the funding compensation, i.e., attractive rewards (Koch 2016). This part of funding, however, increases the visibility of this blockbuster project which distracts attention from other projects. Consequently, the funders need to carry the costs of putting only blockbuster projects in the middle of interest. (4) According to our approach, individuals who continue funding will have to pay an additional tax $\tau$ on their funding. If the funding goal of a project has been reached and a funder is interested in the reward of this project, s/he has to pay $z \cdot(1+\tau)$ instead of paying only the required amount $z$. This tax slightly increases the amount due for funders. All funders that contribute to the project before it reaches its funding goal do not need to pay this tax-funders that decide for supporting projects which have already hit their funding goal have to pay this additional tax on top of the normal funding. Thus, the tax will counter the buy-side pressure that focuses on the rewards. The resulting tax yield is redistributed to those projects that have closely missed their funding goal so that these are finally successfully fundedstarting with the project closest to its goal. Thereby, the funding that projects have reached serves as a proxy for quality in order to avoid funding of low-quality projects. Furthermore, funders are redirected to other projects in a Pigouvian manner because funding the blockbuster project is made less attractive. 
In order to analyze whether a funding redistribution mechanism is able to improve overall funding results on a crowdfunding platform, we aim at testing different taxes on overfunding in form of a simulated policy experiment. As we know from diverse other fields of tax applications, e.g., wage taxation (Stiglitz 1982; Kanbur et al. 1994; Allen 1982), an optimal taxation approach is important to reach best taxation results. In the context of crowdfunding, we deem it especially important to carefully design a taxation approach for a funding redistribution because funders decide dynamically between several projects available on the platform. There are two main effects of a tax that support a successful funding redistribution on the platform. Firstly, funders may continue funding an overfunded project and, thus, pay the tax. In this case, the collected tax can be used to fund undervalued project worth funding ("controlled" redistribution). Secondly, funders may decide against funding a fully funded project because of the tax and decide for another project on the platform. In this case, the money is redistributed by the funders themselves and not through the taxation approach ("uncontrolled" redistribution). Optimally, the funders select other projects that, then, will reach the goal. In contrast, it would be an adverse effect if this money floats to projects that will never reach the funding goal. In this case, the level of successfully raised funds will decrease. Another adverse effect of a taxation would be that funders - who would have funded without the tax-do not find any attractive project on the platform anymore and, thus, spend the money somewhere else. If the funding flows going in unsuccessful projects or off the platform outweigh the positive consequences of a tax, the taxation approach fails to optimize the funding results. However, as long as there are enough funders who find alternatives to successfully funded projects or are willing to pay the additional tax, this mechanism will increase the number of successfully funded projects. The tax has an important advantage over funding caps, i.e., maximum funding levels, because the funders are still allowed to fund the projects of their interest and do not lose their favorite options.

For our policy experiment, we apply different taxation designs as possible countermeasures to tackle overfunding. Using the designed ABM, we aim at analyzing whether different tax designs lead to comparable results or salient differences. Specifically, we apply four types of taxation approaches plus one approach in which overfunding is strictly forbidden ("funding cap").

As a first taxation approach, we apply a constant tax (1) which is applied equally to all funding contributions that support already successfully funded projects, i.e., if a project is fully funded and a funder further supports the project, s/he pays a fixed tax on the amount funded. In the second taxation approach (2), a linear increasing tax is applied. This tax increases linearly from the point at which the project reaches $100 \%$ funding, i.e., at the level of $100 \%$ funding the tax is zero but then increases linearly until it reaches a certain maximum tax value. This end point of the linear increase of the tax is described by a specific level of overfunding. For example, the tax could start at a level of $100 \%$ funding and increases linearly to its maximum at $300 \%$ funding (notes as: " $\max$ at 300\%"). Next, we consider a linear increasing tax with an offset, that does not start with a tax of zero at the level of $100 \%$ funding but with half of the maximum tax. For example, a tax of $5 \%$ starts with $2.5 \%$ and increases linearly to $5 \%$. The maximum of the tax will be reached again at a certain 
(a) Rate of Successfully

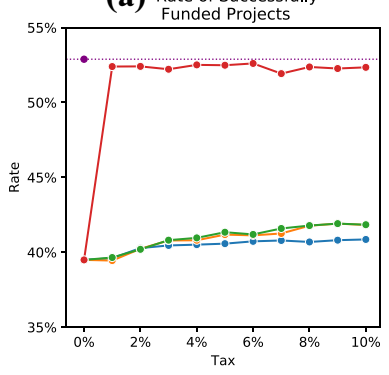

(d) Overfunding Rate

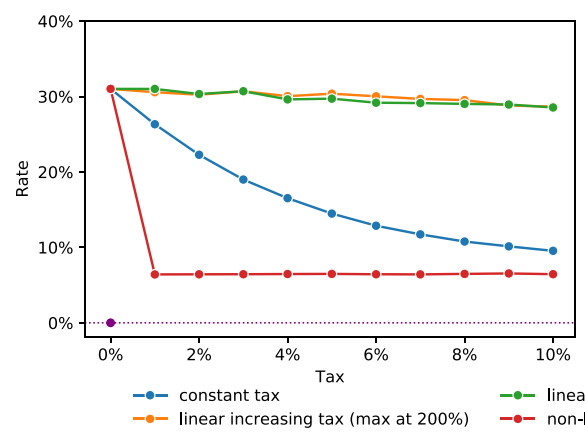

(b) Sum of Successfully

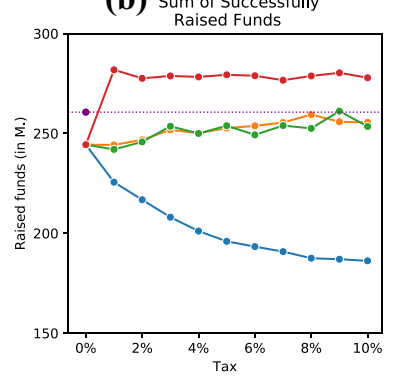

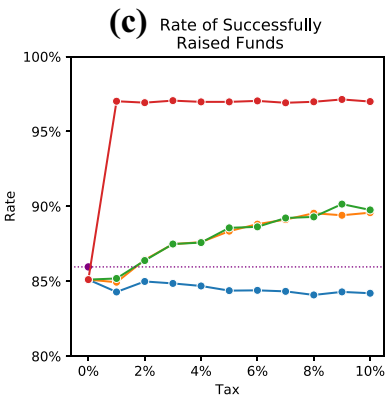

(e) Rate of Alternative Investments

Fig. 4 Results of the sensitivity analysis considering different tax applications and tax levels

point of overfunding - comparable to case (3). We also consider a non-linear tax (4), which increases steeply for low overfunding and then levels off when overfunding further increases. This tax is described by the function $\tau=\frac{x}{(x+a)} \times \tau_{\max }$. Here, $x$ is the amount of overfunding relative to the project goal and $\tau_{\max }$ is the maximum tax against which the formula converges. Hereby, we consider different values for $a$ (e.g., 0.01, 0.05, 0.1, 0.5). Finally, we apply a scenario in which overfunding is strictly forbidden (5).

In the following, we analyze the outcomes of the different tax approaches using the ABM. Therefore, we vary the respective parameters in the sense of a sensitivity analysis to gain a deeper understanding of the reaction of the simulated funders in the model to the different approaches and tax levels applied. Figure 4 provides the result of our sensitivity analysis for different tax approaches. For each of the five different approaches, one representative configuration is presented. Further configurations are presented in the appendix of this paper to avoid an overload of the figures (see Figs. 7, 8, 9 in Appendix 4). For all the taxation approaches, we discuss five curves that characterize the reaction of the ABM to the tax policy. While four of the different approaches are discussed for a spectrum of different tax parametrizations (0-10\%), the approach in which overfunding is strictly forbidden is only given at one point in each of the five graphs. The respective horizontal line is supposed to ease the interpretation of the figures. 
The results of the analysis show that the rate of successfully funded projects increases due to the redistribution of funding for all setups (a). Even in case of no overfunding (funding cap), funders succeed in selecting other projects which, then, become successfully funded. Without any change of policy, we observe a rate of about $39 \%$ successfully funded projects. In case of the constant tax and the two linear increasing tax scenarios, the rate is slightly increasing to $41-42 \%$ successfully funded projects. However, if overfunding is forbidden, the rate of successfully funded projects soars to 53\%. The non-linear tax approach $(a=0.1)$ can almost reach this level. It seems that this non-linear tax better succeeds in exploiting funders' willingness to pay the additional tax or to redistribute their contributions than the other tax types.

Even more important than the rate of successfully funded projects for the platform operators is the sum of successfully raised funds (b). This is important because platform fees are usually calculated based on this figure. Consequently, this figure has a direct influence on platform's revenues. We observe that the constant tax is too inflexible to exploit funders' willingness to pay the additional tax or to redistribute their contributions. The higher the constant tax, the lower is the sum of successfully raised funds. For the two linear increasing tax approaches, we observe slightly increasing sums of successfully raised funds. On the same level, we find the scenario with funding cap. The non-linear tax, however, outperforms the other scenarios and achieves the highest level of raised funds.

We also consider the rate of successfully raised funds (c), which is the sum of successfully raised funds divided by the total sum of raised funds. This rate shows how efficient funds are contributed to the campaigns on the platform. In other words, if this rate is, e.g., $85 \%, 15 \%$ of the funding is refunded because the respective projects are not receiving enough funding (all-or-nothing model). In case of the constant tax, we observe only a very slight decrease of this rate. The rates of both linear tax scenarios are increasing. Again, the non-linear tax outperforms the other approaches and achieves the highest rate of successfully raised funds. The approach of forbidding overfunding achieves a quite low level and is even outperformed by the linear approaches.

For the overfunding rate (d), i.e., the sum of overfunded money divided by the sum of overall raised funds, we observe a level of $31 \%$ if no actions are taken. If overfunding is forbidden, no overfunding is left as a matter of course. For the linear tax scenarios, the overfunding rate keeps quite high and decreases only slightly for higher tax rates. The constant tax better succeeds in reducing overfunding. The nonlinear tax, however, does a quite good job in bringing down the rate of overfunding. Nevertheless, overfunding is still allowed so that funders can choose their favorite project. The rate of overfunding reaches $7 \%$ in this scenario.

In order to understand whether funding is still contributed to the platform or floats off the platform, we analyze the rate of alternative investment (e). This figure reports the sum of alternative investments divided by the sum of all contributions on the crowdfunding platform plus the sum of alternative investments. If the projects on the crowdfunding platform are not attractive enough, funders will spend or invest their money somewhere else. For the constant tax, the highest rate of alternative investments can be observed. All other scenarios achieve better, i.e., lower rates of 
alternative investments outside the platform. In case of the two linear tax scenarios and the non-linear tax scenario the level is kept almost equal at about $71 \%$. The lowest rate of alternative investments is achieved by forbidding overfunding, which is slightly below the results of the linear and non-linear tax applications.

Looking at the other configurations in Appendix 4 (Figs. 7, 8, 9), we find similar results compared to the above discussed configurations. Thereby, the characteristics of the curves only slightly change depending on the nature of the respective configurations. These configurations also provide evidence that the results are robust when marginally changing the parameters. However, since some configurations are more sensitive to parameter changes, we emphasize to carefully choose the respective configurations when comparing different tax applications.

\section{Discussion}

The analysis of the various tax scenarios yields interesting insights of how differently the system might react to policy changes. Obviously, the different approaches have advantages and disadvantages, and the experiment tells us to carefully plan policy changes on crowdfunding platforms in order to avoid negative effects for project initiators, funders, and platform operators.

The increasing rates of successfully funded projects (compared to the baseline scenario) in Fig. 4a indicate that a funding redistribution mechanism is able to help projects to reach the funding goal that the projects would not have reached otherwise. In case of the tax scenarios, both effects play an important role: controlled and uncontrolled funding redistribution. Controlled redistribution is governed by the platform by using the tax income. The uncontrolled redistribution emerges from higher costs for fully funded projects (through the tax), which encourages funders to choose other projects. In case of forbidden overfunding, only the uncontrolled redistribution plays a role because no tax income is available to help projects reach their funding goal. Interestingly, the uncontrolled redistribution can be strong enough to compensate and even over-compensate the controlled funding redistribution. However, this effect can be well explained. Taking a glimpse at Fig. 4b, we see that the policy of forbidding overfunding does not yield the highest sum of raised funds. This means that the controlled distribution process is more efficient in supporting projects and help them reach the funding goal-while the funding cap renders higher sums of raised funds impossible. Although there are relatively less tax revenues available for a controlled redistribution, these tax revenues are more successfully invested in the projects. In the case of forbidden overfunding, a higher amount of funds is redistributed but not as efficiently as in the non-linear tax case. This becomes also obvious from Fig. 4c, in which we see that the rate of successfully raised funds is much higher for the non-linear tax case compared to the no-overfunding scenario. For the crowdfunding platform, it will be very attractive to use an approach that does not only increase the rate of successfully funded projects but that also increases the platform's revenues. Thus, in this experiment, the non-linear tax is very attractive to the platform operators. The non-linear tax is able to yield a high sum of successfully raised funds because it further allows funders to invest in overfunded projects. Thus, 
the funders can still fund their favorite projects while accepting to pay the additional tax.

The constant tax performs quite poorly because it treats all kind of overfunding levels in the same way. A low overfunding level is punished as much as higher overfunding levels. This approach is, thus, too inflexible to consider different types of funders. The linear taxes perform much better by punishing lower levels of overfunding much less than higher levels. By this principle, the willingness of funders to pay taxes is much better exploited. Compared to the linear tax approaches, the nonlinear tax exploits this willingness to pay the additional tax even better and succeeds well in achieving high sums of tax revenues for the redistribution.

In Fig. 4d, we can see that the linear tax approaches perform quite badly in reducing overfunding. The constant tax performs better and leads to a stronger decrease of overfunding. The non-linear tax is the best of the tax approaches when it comes to reducing overfunding. However, this decrease of overfunding is achieved in a way that leaves enough overfunding to be taxed. Moreover, this taxation is at a level that exploits best the funders' willingness to pay the additional tax and, therefore, yields a sufficient tax income for the redistribution mechanism.

Figure $4 \mathrm{e}$ reveals that the constant tax is likely to make overfunding so unattractive that an increasing rate of funds is floating off the platform into alternative investments. The linear and non-linear tax approaches are more flexible and do not lead to the same effect. Instead, the rate of alternative investments keeps almost the same. However, the lowest rate of alternative investments is achieved if overfunding is strictly forbidden. In this scenario, fully funded projects are no longer available and are deactivated for funding. As a consequence, these projects are no longer taken into consideration by the funders when evaluating the attractiveness of the projects. Thus, blockbuster projects are no longer overshadowing other projects and other projects are relatively more attractive. In case of the tax scenarios blockbuster projects are still available although they are already overfunded. This makes them still very appealing in terms of their attractiveness-however, the tax discourages the funders to fund them. Even worse, the other projects are overshadowed and are evaluated as less attractive. As a consequence, the funders choose alternative investments outside the platform because these are more attractive than the crowdfunding projects on the platform. Nevertheless, this effect is quite small so that the linear and non-linear tax approaches are almost on the same level and only slightly above the scenario without overfunding. For the platform, it might be very attractive to keep the funds on the platform. However, from an economic perspective it is not necessarily prudent to keep the money on a certain platform. In case of forbidden overfunding, less funds float off the platform-but is invested in projects that do not reach their funding goal. As a consequence, a higher level of capital is locked in unsuccessful projects and is - at least for some time-not available for a successful investment. It might, thus, be reasonable to let a certain degree of funds float off the platform to be invested rationally somewhere else.

The introduction of a tax could have another positive effect that does not become obvious directly from this analysis. Some funders might wait with their funding and observe the project for some time. However, in case of a tax that is applied as soon as the funding goal is reached, the funders may decide earlier to fund in order to 
avoid the additional costs. This effect would reduce funding hesitation at least if the project is close to its funding goal. This effect counters the bystander effect which is discussed in crowdfunding research (Kuppuswamy and Bayus 2013). It would be a further important effect that supports projects which are close to their goal to finally reach it.

Regarding the question of how crowdfunding serves best all of its stakeholders, it needs to be discussed which consequences the proposed funding redistribution mechanism has for the stakeholders concerned. The results of the analysis show support for introducing a tax for optimizing the overall funding results. We show that for certain tax configurations the rate of successfully funded projects increases considerably. Nevertheless, the results also indicate that the tax level needs to be selected carefully. In order to select the optimal tax configuration, advantages and disadvantages have to be balanced. It seems that a non-linear tax with an appropriate curve shape that considers well the different types of funders succeeds best in increasing the rate of successfully funded projects while yielding a satisfying level of raised funds and, thus, of collected fees for the platform.

For our analysis, we use data of a real online platform for initialization and parametrization. In the given setup, the decision-making behavior is modeled without specific information about funders' price sensitivity. The proposed model is extendable and allows for considering such information. This would enhance the model to find an optimal level of tax for a certain crowdfunding system. The inclusion of this information, however, means no fundamental change in the methodology but leads to adjustments in the decision behavior.

Research on individuals' funding behavior has unveiled several interesting effects. The inclusion of all these effects is far beyond the scope of this paper. However, we are able to show that the method of funding decision behavior applied in our model is able to embrace such effects. The introduction of other effects is at the liberty of further research and of practitioners aiming at investigating the system for specific purposes. Finally, we point out that-apart from the alternative investment possibility considered in our model-our model takes an on-platform perspective. Definitely, there are also questions that need a model of the complete market for platforms - in order to, for example, analyze a possible effect of migration (e.g., of funders or project initiators) that takes place because of modifications of the funding model or policy changes on a platform. However, we leave this perspective for future research. Moreover, our main focus is on reward-based crowdfunding. For other types of crowdfunding (e.g., crowdlending), we advise to consider further specific characteristics and data.

\section{Conclusion}

Although research has engaged with funding outcomes of campaigns and with several phenomena of individuals' funding behavior, interestingly, literature concerning the quality or potential optimization of overall funding results is utterly scarce. Moreover, while researchers regularly use data from platforms or conduct surveys, research methods concerning simulations are almost completely neglected. The lack 
of simulation-based research in the field of crowdfunding as well as the missing research on the question of how the overall results derived through crowdfunding could be analyzed or even enhanced constitute a perfect fit. Therefore, we propose an agent-based model that considers individuals' funding behavior and succeeds well in replicating the key characteristics of the funding distributions of crowdfunding platforms.

The contribution of this paper is twofold. Firstly, the paper contributes to the crowdfunding literature by discussing how crowdfunding serves best all of its stakeholders. Following the ideas of mechanism design and market engineering, we propose different taxation mechanisms to internalize overfunding externalities and apply our agent-based model in order to evaluate our proposed mechanisms by means of sensitivity analyses. Thereby, we transfer the economic theory of internalizing externalities to the landscape of crowdfunding. Our results show support for applying a taxation mechanism to tackle the problem of massive project overfunding. We show, that applying certain taxation mechanism can lead to increasing rates of successfully funded projects and sums of successfully raised funds. In this sense, we deliver an interesting example of market engineering in the field of online crowdfunding platforms. Secondly, this paper gives a comprehensible outline of how to develop agent-based models in the field of crowdfunding and gives insights into the design concepts. In previous research, we only find rudimentary decision-making using pure random variables. The decision-making behavior of agents seemed to be a big hurdle for developing crowdfunding agent-based models that are more realistic. To address this gap, we engage with proposing a well-founded approach using the OWA operator and the MADM method. Thereby, we contribute to agent-based model development techniques and propose how decision behavior can be modeled. In this context, we also provide a theoretical foundation for our model showing how to align agents' decision-making behavior to self-determination theory. We derive five principles from this theory and discuss how they are addressed in the agents' decision mechanism applied in our model. Of course, simplifications are needed and a system's complexity can only be reduced applying reasonable simplifications. Nevertheless, we advise to carefully regard possible effects of decision-making that might be important to certain scenarios or specific questions of interest. We address researchers and practitioners alike and invite research to further consider this powerful way of gaining new insights and to enhance the crowdfunding models applied.

\section{Appendix 1: Further details regarding the model design}

See Fig. 5. For simplification in this illustration, the variable parameter configuration in the observer class represents all configuration parameters and the methods getProjectProperties() as well as setProjectProperties() in the Project class represent all getter and setter methods. 


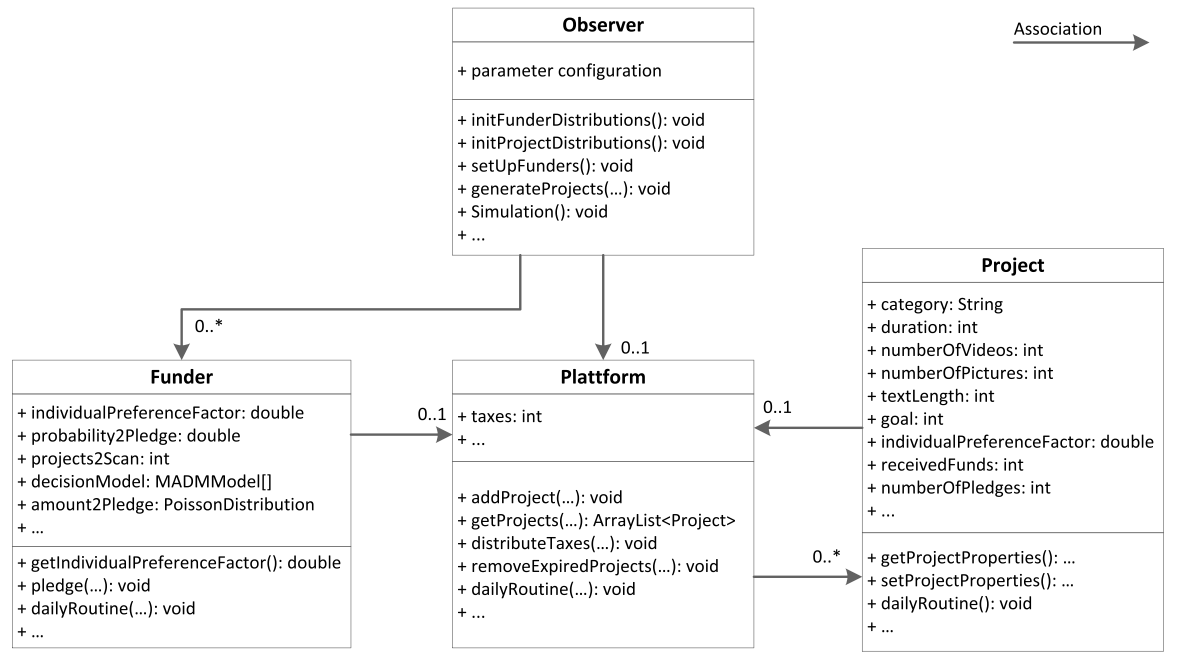

Fig. 5 UML diagram illustrating the structure of the most important classes of the ABM

\section{Appendix 2: Descriptive statistics of the data set used for calibration of the model}

See Tables 2, 3 .

Table 2 Descriptive statistics of the crowdfunding campaigns' properties in our data set

\begin{tabular}{lllllllll}
\hline & count & mean & std & $\min$ & $25 \%$ & $50 \%$ & $75 \%$ & $\max$ \\
\hline Goal & 31,680 & $14,080.78$ & $28,150.56$ & 1 & 1500 & 5000 & 13,500 & 276,855 \\
Duration of funding period & 31,680 & 32.64 & 11.35 & 1 & 30 & 30 & 33 & 88 \\
Number of videos & 31,669 & 0.87 & 0.88 & 0 & 0 & 1 & 1 & 5 \\
Number of pictures & 31,662 & 4.35 & 7.35 & 0 & 0 & 0 & 6 & 41 \\
Text length & 31,680 & 498.67 & 467.90 & 1 & 173 & 342 & 669 & 2755 \\
\hline
\end{tabular}


Table 3 Distribution of categories among crowdfunding campaigns in our data set

\begin{tabular}{ll}
\hline Category & Share $(\%)$ \\
\hline Art & 7.66 \\
Comics & 2.36 \\
Crafts & 3.61 \\
Dance & 1.33 \\
Design & 10.09 \\
Fashion & 7.14 \\
Film \& Video & 12.67 \\
Food & 7.95 \\
Games & 10.90 \\
Journalism & 1.18 \\
Music & 9.57 \\
Photography & 2.58 \\
Publishing & 10.01 \\
Technology & 10.97 \\
Theater & 1.99 \\
\hline
\end{tabular}

\section{Appendix 3: Parameter configuration and robustness checks}

See Fig. 6 and Tables 4, 5, 6.

(a) Best configuration

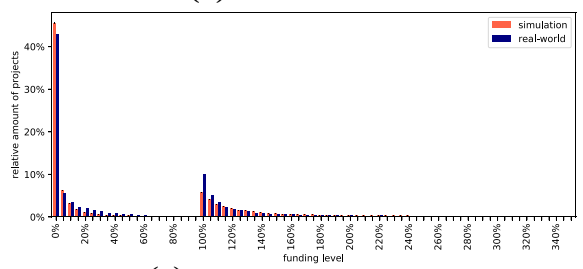

(c) Robustness configuration 2

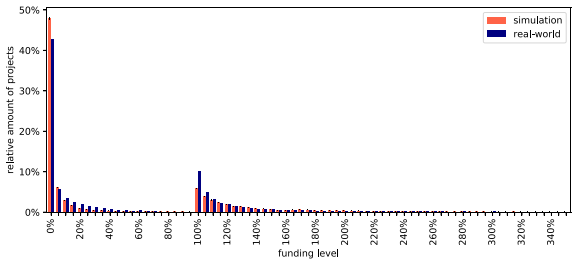

(e) Robustness configuration 4

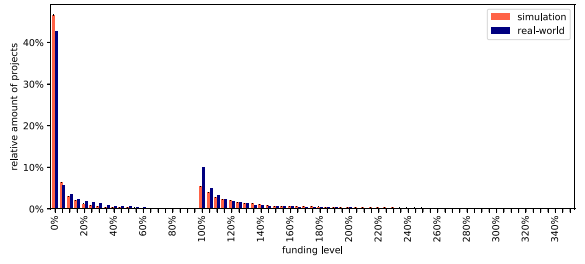

(b) Robustness configuration 1

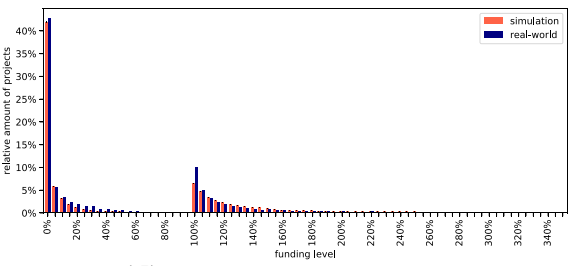

(d) Robustness configuration 3

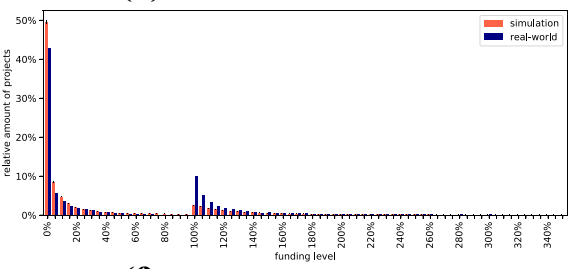

(f) Robustness configuration 5

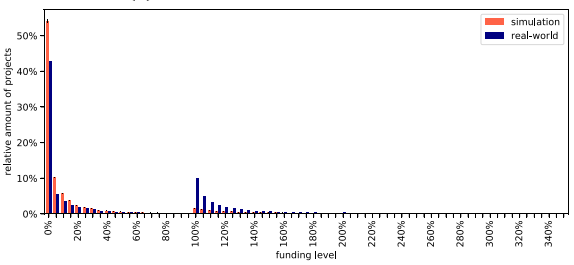

Fig. 6 Resulting distributions of funding outcomes (robustness checks) 
Table 4 Parameter configuration for calibrating the ABM

\begin{tabular}{lll}
\hline Name & Configurations & Best configuration \\
\hline Registered funders & $\{2 \mathrm{M} ; 2.25 \mathrm{M} ; 2.5 \mathrm{M} ; 3 \mathrm{M} ; 5 \mathrm{M}\}$ & $2,250,000$ \\
Initial funding (number of initial pledges) & $\{1 ; 2 ; 5 ; 10\}$ & 5 \\
Observed projects & $\{100 ; 200 ; 500 ; 1000\}$ & 1000 \\
Category preferenecs & $\{1 ; 2 ; 3 ; 4 ; 5\}$ & 3 \\
Funding threshold & $\{0.5 ; 0.55 ; 0.6 ; 0.65 ; 0.7 ; 0.75 ; 0.8\}$ & 0.6 \\
Overfunding cost-type function & \\
\hline
\end{tabular}

$*_{\mathrm{x}}=$ funding received relative to project goal $-1, * * a \in\{0.01,0.05,0.1,0.5\}$

Table 5 Parameter configuration of the robustness checks

\begin{tabular}{|c|c|c|c|c|c|}
\hline Name & Registered funders & Initial funding & Observed projects & $\begin{array}{l}\text { Category } \\
\text { prefer- } \\
\text { ences }\end{array}$ & $\begin{array}{l}\text { Funding } \\
\text { threshold }\end{array}$ \\
\hline Best Configuration & $2,250,000$ & 5 & 1000 & 3 & 0.6 \\
\hline $\begin{array}{l}\text { Robustness configura- } \\
\text { tion } 1\end{array}$ & $3,000,000$ & 5 & 1000 & 3 & 0.6 \\
\hline $\begin{array}{l}\text { Robustness configura- } \\
\text { tion } 2\end{array}$ & $2,250,000$ & 4 & 1000 & 3 & 0.6 \\
\hline $\begin{array}{l}\text { Robustness configura- } \\
\text { tion } 3\end{array}$ & $2,250,000$ & 5 & 500 & 3 & 0.6 \\
\hline $\begin{array}{l}\text { Robustness configura- } \\
\text { tion } 4\end{array}$ & $2,250,000$ & 5 & 1000 & 4 & 0.6 \\
\hline $\begin{array}{l}\text { Robustness configura- } \\
\text { tion } 5\end{array}$ & $2,250,000$ & 5 & 1000 & 3 & 0.65 \\
\hline
\end{tabular}




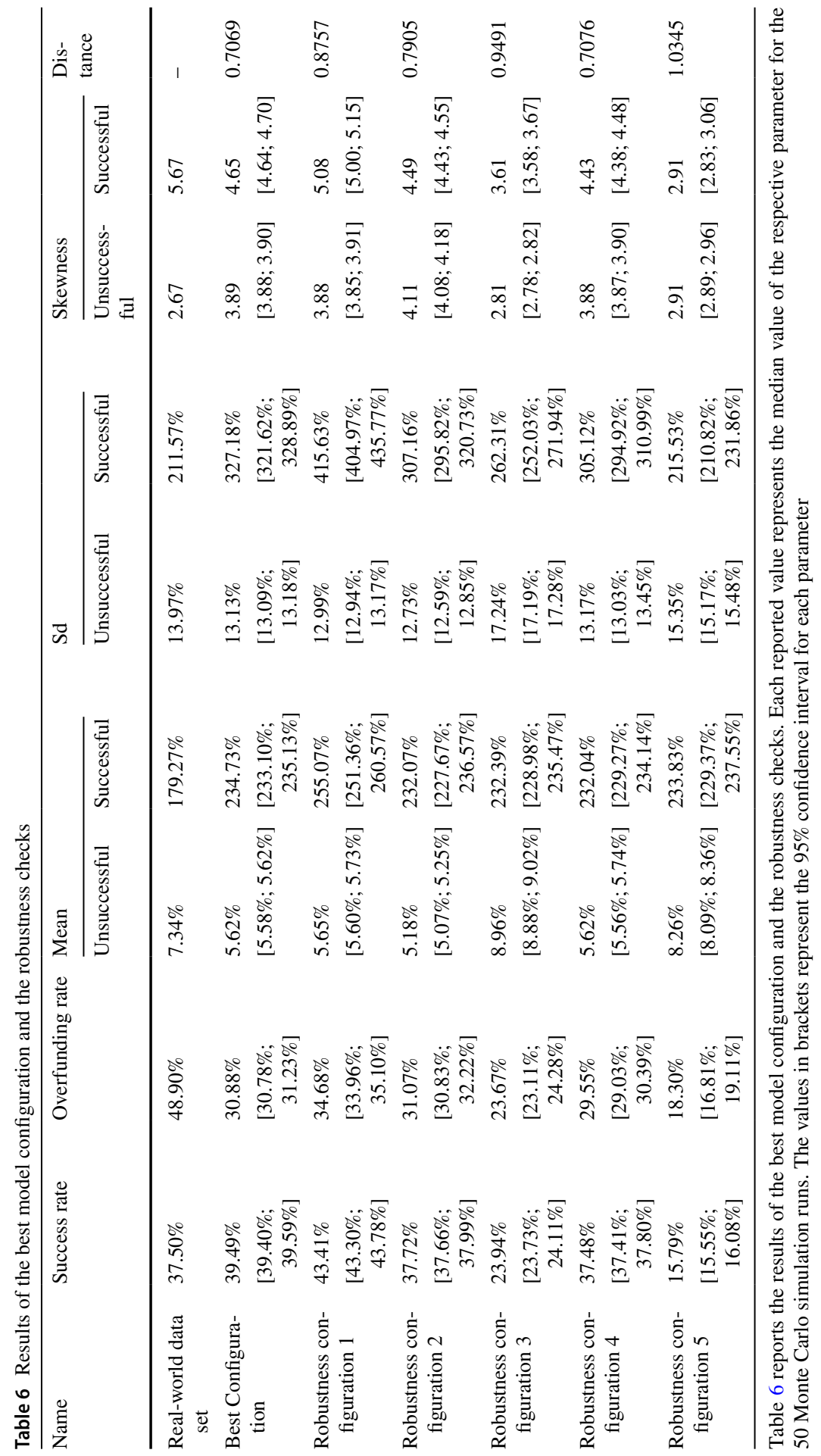




\section{Appendix 4: Results for further configurations of the different tax applications}

See Figs. 7, 8 and 9.
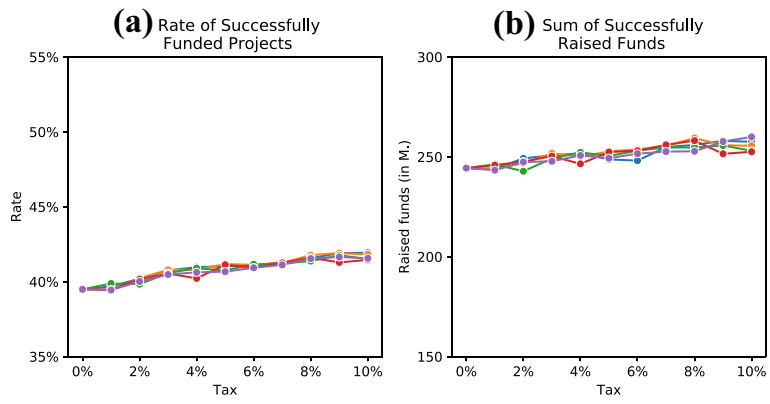

(d) Overfunding Rate

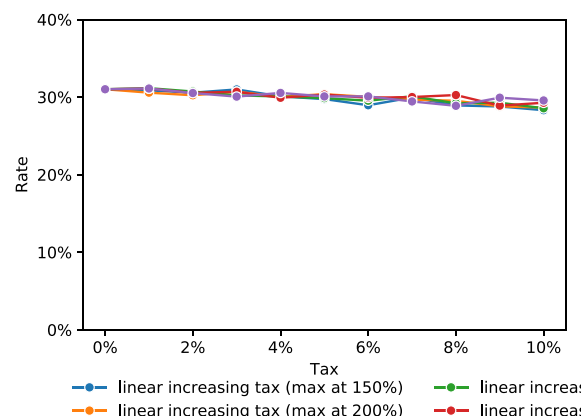

- - linear increasing tax (max at $200 \%)$

- - linear increasing tax ( $\max$ at $400 \%$ ) (c) Rate of Successfully

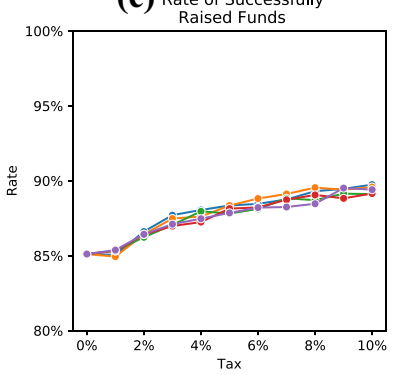

(e) Rate of Alternative Investments

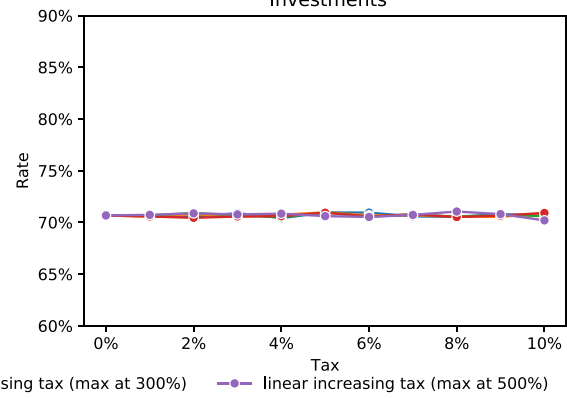

Tax
-

Fig. 7 Results of the sensitivity analysis considering different tax applications and tax levels (different configurations of the linear increasing tax) 
(a) Rate of Successfully

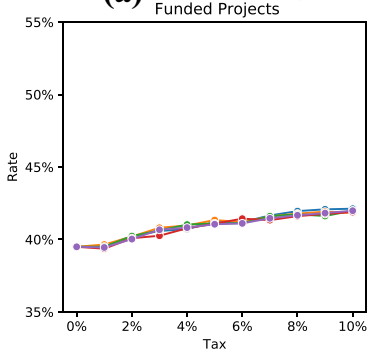

(b) Sum of Successfully

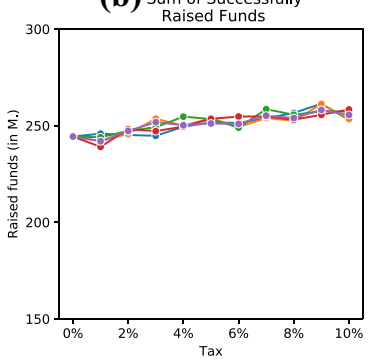

(c) Rate of Successfully

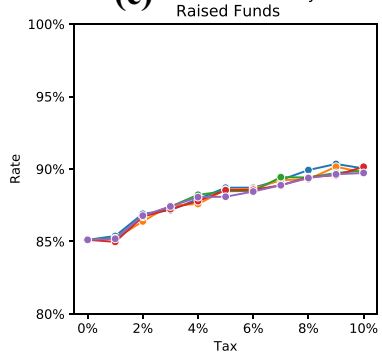

(e) Rate of Alternative Investments

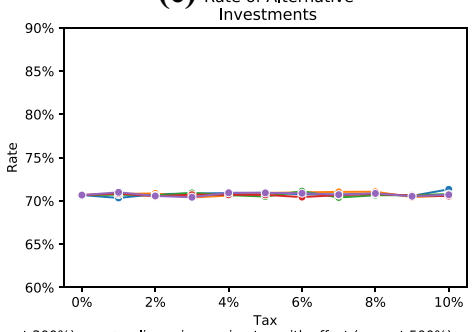

- linear increasing tax with offset ( $\max$ at $150 \%$ ) - - linear increasing tax with offset ( $\max$ at $300 \%$ )

linear increasing tax with offset ( $\max$ at $150 \%)$
linear increasing tax with offset $(\max$ at $200 \%)$

Fig. 8 Results of the sensitivity analysis considering different tax applications and tax levels (different configurations of the linear increasing tax with offset)

(a) Rate of Successfully Funded Projects

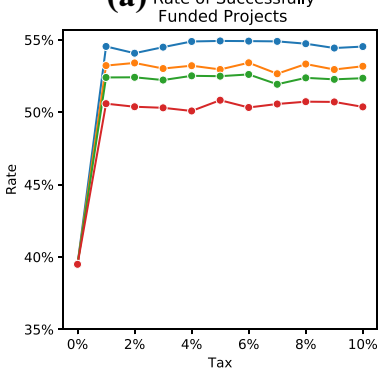

(d) Overfunding Rate

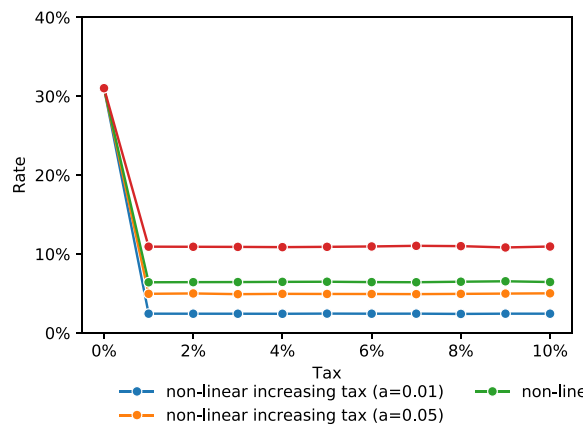

(c) Rate of Successfully Raised Funds

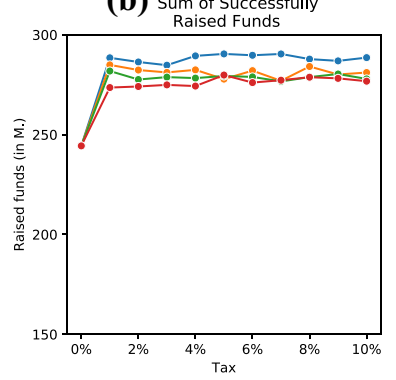

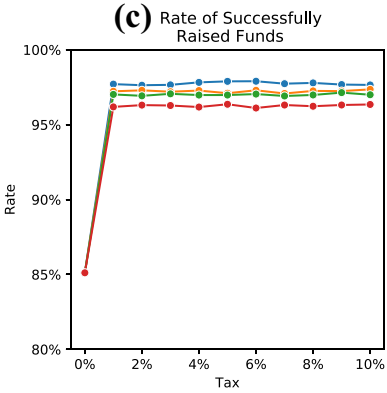

(f) Rate of Alternative Investments

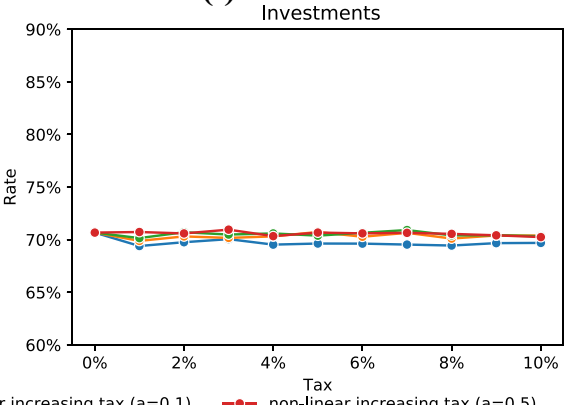

Fig. 9 Results of the sensitivity analysis considering different tax applications and tax levels (different configurations of the non-linear increasing tax) 
Funding Open Access funding enabled and organized by Projekt DEAL.

\section{Declarations}

Conflict of interest The authors declare that they have no conflict of interest.

Open Access This article is licensed under a Creative Commons Attribution 4.0 International License, which permits use, sharing, adaptation, distribution and reproduction in any medium or format, as long as you give appropriate credit to the original author(s) and the source, provide a link to the Creative Commons licence, and indicate if changes were made. The images or other third party material in this article are included in the article's Creative Commons licence, unless indicated otherwise in a credit line to the material. If material is not included in the article's Creative Commons licence and your intended use is not permitted by statutory regulation or exceeds the permitted use, you will need to obtain permission directly from the copyright holder. To view a copy of this licence, visit http://creativecommons.org/licen ses/by/4.0/.

\section{References}

Acharya VV, Pedersen LH, Philippon T, Richardson M (2010) A tax on systemic risk. In: Proceedings of the post-crisis regulatory reforms to secure financial stability: 2010 KDI international conference, pp 3-39

Agrawal A, Catalini C, Goldfarb A (2015) Crowdfunding: geography, social networks, and the timing of investment decisions. J Econ Manag Strat 24(2):253-274

Aidt TS (1998) Political internalization of economic externalities and environmental policy. J Public Econ 69(1):1-16

Alaei S, Malekian A, Mostagir M (2016) A dynamic model of crowdfunding. In: Conitzer V, Bergemann D, Chen Y (eds) ACM conference. Maastricht, Netherlands

Allen F (1982) Optimal linear income taxation with general equilibrium effects on wages. J Public Econ 17(2):135-143

Allison TH, Davis BC, Short JC, Webb JW (2014) Crowdfunding in a prosocial microlending environment: examining the role of intrinsic versus extrinsic cues. Entrep Theory Pract 39(1):53-73

Ballot G, Mandel A, Vignes A (2015) Agent-based modeling and economic theory: where do we stand? J Econ Interact Coord 10(2):199-220

Barbi M, Bigelli M (2015) Crowdfunding practices in and outside the us. Working Paper (Version: 2015/03/12)

Baumol WJ, Oates WE (1971) The use of standards and prices for protection of the environment. Swed J Econ 73(1):42-54

Beaulieu T, Sarker S, Sarker S (2015) A conceptual framework for understanding crowdfunding. Commun Assoc Inf Syst 37:1-31

Bonabeau E (2002) Agent-based modeling: methods and techniques for simulating human systems. Proc Natl Acad Sci USA 99(3):7280-7287

Bretschneider U, Knaub K, Wieck E (2014) Motivations for crowdfunding: What drives the crowd to invest instart-ups? In: Proceedings of the twenty-second European conference on information systems (ECIS'14), Tel Aviv: Israel

Buchanan JM, Stubblebine WC (1962) Externality. Economica 29(116):371-384

Burtch G (2011) Herding behavior as a network externality. In: Proceedings of the thirty second international conference on information systems (ICIS'11), Shanghai: China

Burtch G, Chan J (2014) Reducing medical bankruptcy through crowdfunding: Evidence from give forward. In: Proceedings of the thirty fifth international conference on information systems (ECIS'14), Auckland: New Zealand

Burtch G, Ghose A, Wattal S (2014) Cultural differences and geography as determinants of online pro-social lending. MIS Q 38(3):773-794

Burtch G, Ghose A, Wattal S (2015) The hidden cost of accommodating crowdfunder privacy preferences: a randomized field experiment. Manag Sci 61(5):949-962 
Chang JW (2016) The economics of crowdfunding. Working Paper (Version: 2016/08/30)

Cholakova M, Clarysse B (2015) Does the possibility to make equity investments in crowdfunding projects crowd out reward-based investments? Entrep Theory Pract 39(1):145-172

Coase RH (1960) The problem of social cost. J Law Econ 3:1-44

Dahlman CJ (1979) The problem of externality. J Law Econ 22(1):141-162

Deci EL, Ryan RM (1987) The general causality orientations scale: self-determination in personality. J Res Pers 19:109-134

Deci EL, Ryan RM (2000) The "what" and "why" of goal pursuits: human needs and the self-determination of behavior. Psychol Inq 11(4):227-268

Deci EL, Ryan RM (2012) Self-determination theory. In: Lange V, Paul AM, Kruglanski AW, Higgins ET (eds) Handbook of theories of social psychology. SAGE Publications, London

Dijkman RM, Sprenkels B, Peeters T, Janssen A (2015) Business models for the internet of things. Int J Inf Manag 35(6):672-678

Doshi A (2014) The impact of high performance outliers on two-sided platforms: Evidence from crowdfunding. Working Paper (Version: 2014/10/20)

Fagiolo G, Guerini M, Lamperti F, Moneta A, Roventini A (2019) Validation of agent-based models in economics and finance. Computer simulation validation. Springer, Berlin, pp 763-787

Fischer P, Krueger JI, Greitemeyer T, Vogrincic C, Kastenmuller A, Frey D, Heene M, Wicher M, Kainbacher M (2011) The bystander-effect: a meta-analytic review on bystander intervention in dangerous and non-dangerous emergencies. Psychol Bull 137(4):517-537

Fullér R (1996) Exploring the limits of support systems. In: Carlsson C (ed) Exploring the limits of support systems. TUCS General Publications, Turkey, pp 85-104

García-Magariño I, Medrano C, Lombas AS, Barrasa A (2016) A hybrid approach with agent-based simulation and clustering for sociograms. Inf Sci 345:81-95

Gerber EM, Hui JS, Kuo PY (2012) Crowdfunding: Why people are motivated to post and fund projects on crowdfunding platforms. In: Proceedings of the international workshop on design, influence, and social technologies: techniques, impacts and ethics, vol 2

Gomber P, Koch JA, Siering M (2017) Digital finance and fintech: current research and future research directions. J Bus Econ 87(5):537-580

Grimm V, Berger U, Bastiansen F, Eliassen S, Ginot V, Giske J, Goss-Custard J, Grand T, Heinz SK, Huse G, Huth A, Jepsen JU, Jørgensen C, Mooij WM, Müller B, Pe'er G, Piou C, Railsback SF, Robbins AM, Robbins MM, Rossmanith E, Rüger N, Strand E, Souissi S, Stillman RA, Vabø R, Visser U, DeAngelis DL (2006) A standard protocol for describing individual-based and agentbased models. Ecol Model 198(1-2):115-126

Grimm V, Berger U, DeAngelis DL, Polhill JG, Giske J, Railsback SF (2010) The odd protocol: a review and first update. Ecol Model 221(23):2760-2768

Grimm V, Railsback SF, Vincenot CE, Berger U, Gallagher C, DeAngelis DL, Edmonds B, Ge J, Giske J, Groeneveld J et al (2020) The odd protocol for describing agent-based and other simulation models: a second update to improve clarity, replication, and structural realism. J Artif Soc Soc Simul 23:2

Gupta AK, Prakash A (1993) On internalization of externalities. Working Paper (No. 1126)

Hurwicz L, Reiter S (2006) Designing economic mechanisms. Cambridge University Press, Cambridge

Kanbur R, Keen M, Tuomala M (1994) Optimal non-linear income taxation for the alleviation of income-poverty. Eur Econ Rev 38(8):1613-1632

Keller JM (2008) First principles of motivation to learn and e3-learning. Distance Educ 29(2):175-185

Kim J, Lee M, Cho D, Lee B (2016) Are all spillovers created equal? The impact of blockbusters and the composition of backers in online crowdfunding. In: Proceedings of the thirty seventh international conference on information systems (ICIS'16), Dublin: Ireland

Klein D, Marx J, Fischbach K (2018) Agent-based modeling in social science, history, and philosophy. an introduction. Hist Soc Res 43(1 (163)):7-27

Koch JA (2016) The phenomenon of project overfunding on online crowdfunding platforms: analyzing the drivers of overfunding. In: Proceedings of the twenty-fourth European conference on information systems (ECIS'16), İstanbul: Turkey

Koch JA (2017) A framework for the notion of 'utility' in the landscape of crowdfunding. In: Proceedings of the twenty-fifth european conference on information systems (ECIS'17), Guimarães: Portugal 
Koch JA, Cheng Q (2016) The role of qualitative success factors in the analysis of crowdfunding success: evidence from kickstarter. In: Proceedings of the 20th Pacific Asia conference on information systems (PACIS'16), Chiayi: Taiwan

Koch JA, Siering M (2015) Crowdfunding success factors: The characteristics of successfully funded projects on crowdfunding platforms. In: Proceedings of the twenty-third European conference on information systems (ECIS'15), Münster: Germany

Kuppuswamy V, Bayus BL (2013) Crowdfunding creative ideas: The dynamics of project backers in kickstarter. Working Paper (Version: 2013/03/16)

Latan B, Nida S (1981) Ten years of research on group size and helping. Psychol Bull 89(2):308-324

Law AM (2015) Simulation modeling and analysis. McGraw-Hill series in industrial engineering and management science, 5th edn. McGraw-Hill Education, New York

Lee YC, Yen CH, Fu WT (2016) Improving donation distribution for crowdfunding: an agent-based model. In: Proceedings of the 9th international conference on social, cultural, and behavioral modeling, Washington (DC): USA

Li Z, Duan JA (2014) Dynamic strategies for successful online crowdfunding. Working Paper (Version: 2014/09)

Liu J, Yang L, Wang Z, Hahn J (2015) Winner takes all? The "blockbuster effect" in crowdfunding platforms. In: Proceedings of the thirty sixth international conference on information systems (ICIS'15), Fort Worth: USA

Lu CT, Xie S, Kong X, Yu PS (2014) Inferring the impacts of social media on crowdfunding. In: Carterette B, Diaz F, Castillo C, Metzler D (eds) 7th ACM international conference, New York (NY): USA, pp 573-582

Macal CM, North MJ (2010) Tutorial on agent-based modelling and simulation. J Simul 4:151-162

Malave I (2012) Why kickstarter should more fully integrate social media. Working Paper (Version: 2012/11)

McFadden D (1989) A method of simulated moments for estimation of discrete response models without numerical integration. Econom J Econ Soc 20:995-1026

Merton RK (1968) The matthew effect in science. Science 159(3810):56-63

Mollick E (2014) The dynamics of crowdfunding: an exploratory study. J Bus Ventur 29(1):1-16

Moritz A, Block JH (2016) Crowdfunding: a literature review and research directions. FGF Stud Small Bus Entrep 2:25-53

Neumann D, Maekioe J, Weinhardt C (2005) Came-a tool set for configuring electronic markets. In: Proceedings of the thirteenth European conference on information systems (ECIS'05), Regensburg: Germany

Nikolic I, Ghorbani A (2011) A method for developing agent-based models of socio-technical systems. In: International conference on networking, sensing and control (ICNSC'11). Delft, Netherlands, pp 44-49

Olsen RA (1996) Implications of herding behavior for earnings estimation, risk assessment, and stock returns. Financ Anal J 52(4):37-41

Pigou AC (1920) The economics of welfare. MacMillan and Co., Limited, London

Pitschner S, Pitschner-Finn S (2014) Non-profit differentials in crowd-based financing: evidence from 50,000 campaigns. Econ Lett 123(3):391-394

Prechter RR (2001) Unconscious herding behavior as the psychological basis of financial market trends and patterns. J Psychol Financ Mark 2(3):120-125

Ryan RM, Deci EL (2000) Self-determination theory and the facilitation of intrinsic motivation, social development, and well-being. Am Psychol 55(1):68-78

Ryan RM, Deci EL (2004) Overview of self-determination theory: an organismic dialectical perspective. In: Deci EL, Ryan RM (eds) Handbook of self-determination research. The University of Rochester Press, Rochester

Ryan RM, Sheldon KM, Kasser T, Deci EL (1996) All goals are not created equal: an organismic perspective on the nature of goals and their regulation. In: Gollwitzer PM, Bargh JA (eds) Psychology of action: linking cognition and motivation to behavior. Guilford, New York, pp 7-26

Ryan RM, Kuhl J, Deci EL (1997) Nature and autonomy: an organizational view of social and neurobiological aspects of self-regulation in behavior and development. Dev Psychopathol 9:701-728

Savage LJ (1972) The foundations of statistics. Courier Corporation, North Chelmsford

Sharpanskykh A, Haest R (2015) An agent-based model to study effects of team processes on compliance with safety regulations at an airline ground service organization. In: Proceedings of the 
18th international conference on principles and practice of multi-agent systems (PRIMA'15). Springer, Bertinoro: Italy

Stiglitz JE (1982) Self-selection and pareto efficient taxation. J Public Econ 17(2):213-240

Timmers P (1998) Business models for electronic markets. Electron Mark 8(2):3-8

Vansteenkiste M, Niemiec CP, Soenens B (2010) The development of the five mini-theories of selfdetermination theory: an historical overview, emerging trends, and future directions. In: Urdan TC, Karabenick SA (eds) The decade ahead: theoretical perspectives on motivation and achievement, advances in motivation and achievement, vol 16. Emerald Group Publishing Limited, Bingley, pp 105-165

Weinhardt C, Holtmann C, Neumann D (2003) Market-engineering. Wirtschaftsinformatik 45(6):635-640

Williamson OE (1971) The vertical integration of production: market failure considerations. Am Econ Rev 61(2):112-123

Winker P, Gilli M, Jeleskovic V (2007) An objective function for simulation based inference on exchange rate data. J Econ Interact Coord 2(2):125-145

Xu Z (2015) Uncertain multi-attribute decision making. Springer, Heidelberg

Yager RR (1988) On ordered weighted averaging aggregation operators in multicriteria decisionmaking. IEEE Trans Syst Man Cybern 18(1):183-190

Yang Y, Wang HJ, Wang G (2016) Understanding crowdfunding processes: a dynamic evaluation and simulation approach. J Electron Commerce Res 17(1):47-64

Zhang J (2004) A dynamic model of residential segregation. J Math Sociol 28(3):147-170

Zhang J, Liu P (2012) Rational herding in microloan markets. Manag Sci 58(5):892-912

Zvilichovsky D, Inbar Y, Barzilay O (2015) Playing both sides of the market: success and reciprocity on crowdfunding platforms. Working Paper (Version: 2015/09)

Publisher's Note Springer Nature remains neutral with regard to jurisdictional claims in published maps and institutional affiliations. 